\title{
WOMEN'S SUBJECTIVE AND OBJECTIVE HEALTH OVER TIME: THE ROLE OF PSYCHOSOCIAL CONDITIONS AND PHYSIOLOGICAL STRESS RESPONSES
}

Christin Mellner

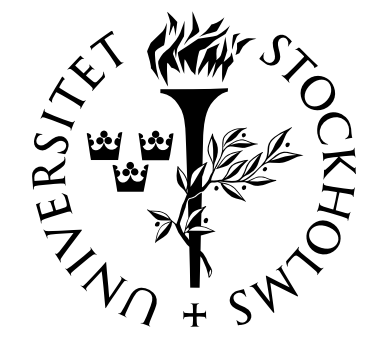

DEPARTMENT OF PSYCHOLOGY STOCKHOLM UNIVERSITY 2004 
Doctoral Dissertation 2004

Department of Psychology

Stockholm University

S-106 91 Stockholm, Sweden

\begin{abstract}
Today, health problems are likely to have a complex and multifactorial etiology, whereby psychosocial factors interact with behaviour and bodily responses. Women generally report more health problems than men. The present thesis concerns the development of women's health from a subjective and objective perspective, as related to psychosocial living conditions and physiological stress responses. Both crosssectional and longitudinal studies were carried out on a representative sample of women. Data analysis was based on a holistic person-oriented approach as well as a variable approach. In Study I, the women's self-reported symptoms and diseases as well as self-rated general health status were compared to physician-rated health problems and ratings of the general health of the women, based on medical examinations. The findings showed that physicians rated twice as many women as having poor health compared to the ratings of the women themselves. Moreover, the symptom "a sense of powerlessness" had the highest predictive power for self-rated general health. Study II investigated individual and structural stability in symptom profiles between adolescence and middle-age as related to pubertal timing. There was individual stability in symptom reporting for nearly thirty years, although the effect of pubertal timing on symptom reporting did not extend into middle-age. Study III explored the longitudinal and current influence of socioeconomic and psychosocial factors on women's selfreported health. Contemporary factors such as job strain, low income, financial worries, and double exposure in terms of high job strain and heavy domestic responsibilities increased the risk for poor self-reported health in middle-aged women. In Study IV, the association between self-reported symptoms and physiological stress responses was investigated. Results revealed that higher levels of medically unexplained symptoms were related to higher levels of cortisol, cholesterol, and heart rate. The empirical findings are discussed in relation to existing models of stress and health, such as the demand-control model, the allostatic load model, the biopsychosocial model, and the multiple role hypothesis. It was concluded that women's health problems could be reduced if their overall life circumstances were improved. The practical implications of this might include a redesign of the labour market giving women more influence and control over their lives, both at and away from work.
\end{abstract}

Key words: health, medically unexplained symptoms, females, longitudinal, psychosocial, stress

2004 Christin Mellner

ISBN 91-7265-853-3

Intellecta Docusys, Sollentuna 2004 


\section{Acknowledgements}

Many people have joined me on this journey and contributed to the accomplishments of this thesis. First, I wish to express my gratitude to my supervisor, Ulf Lundberg, for initiating me to the field of stress psychology, and for his invaluable guidance and support over the years. Further thanks go to Gunilla Krantz, my second supervisor, for her advice and assistance with my work as well as her inspiration and encouragement, and Lars R. Bergman, my third supervisor, for scientific and statistical guidance. I am also obliged to David Magnusson and Bertil Törestad for giving me the privilege of working within the IDA program (Individual Development and Adaptation) many years ago, inspiring me to the first thought of a doctoral thesis.

During my doctoral studies at the Department, I have had the company of many wonderful people. I would especially like to thank Torun Lindholm, Juliska Kansi, Bassam El-Khouri, Maria Larsson, and Eva Chinapah for warm friendship and stimulating conversations.

My very special thanks go to my family and friends, in particular my mother Annicka, and Martina, Janna, and Katti, for always being there. Lastly, my thoughts go to my beloved children Mikaela, Rebecka, and Fabian. You are the joy of my life! 


\section{List of publications}

This dissertation is based on the following four studies:

I

Self- and physician-rated general health in relation to symptoms and diseases among women. (2003). Psychology, Health, and Medicine, 8, 123-135.

II

Symptom development and timing of menarche: A longitudinal study. (2004). International Journal of Methods in Psychiatric Research, 13, 40-53.

III

Psychosocial conditions and self-reported health among women. A longitudinal study. (submitted). International Journal of Behavioral Medicine.

IV

Medically unexplained symptoms in women as related to physiological stress responses. (submitted). Stress and Health. 


\section{Contents}

Introduction

$\begin{array}{ll}\text { General aim of the thesis } & 7\end{array}$

$\begin{array}{ll}\text { Theoretical framework } & 7\end{array}$

$\begin{array}{ll}\text { Holistic interactionism } & 7\end{array}$

The person-oriented approach $\quad 8$

$\begin{array}{ll}\text { Stress and health } & 9\end{array}$

The biopsychosocial model 10

The allostatic load model 10

The demand-control model 12

$\begin{array}{lr}\text { The multiple role hypothesis } & 12\end{array}$

Defining stress 13

$\begin{array}{ll}\text { Psychological stress } & 13\end{array}$

$\begin{array}{ll}\text { Physiological stress } & 14\end{array}$

The SAM-system 16

Assessment of catecholamines 17

The HPA-axis 17

Assessment of cortisol 19

Defining health 20

Self-rated health $\quad 21$

Measuring self-rated health 23

Self-reported symptoms 25

Gender differences in symptom reporting 25

Somatisation 26

Somatic interpretation and attribution theory 27

$\begin{array}{ll}\text { Sensitization } & 28\end{array}$

Symptom reporting and personality 28

Biological maturation $\quad 29$

Gender research 30

Specific aims of the thesis $\quad 32$ 
Study population and setting

Study I

Study II

Study III

Study IV

Statistical methods

Study I

Study II

Study III

Study IV

Study I Self- and physician-rated general health in relation to symptoms and diseases among women. 36

Study II Symptom development and timing of menarche:

A longitudinal study.

Study III Psychosocial conditions and self-reported health among women. A longitudinal study.

Study IV Medically unexplained symptoms in women as related to physiological stress responses.

General discussion

Shortcomings and limitations

Concluding remarks 


\section{Introduction}

\section{General aim of the thesis}

The general aim of this thesis was to study subjective evaluations of health in relation to clinical ratings of health based on medical examinations, as well as physiological stress responses related to common, medically unexplained symptoms among middleaged women representing the general population in Sweden. Thus, health was defined in a broader perspective including the subjective experience of one's health in terms of self-reports of general health status, physical and mental symptoms, and self-reported diseases, as well as evaluations of health according to physician ratings, and the assessment of physiological stress responses. In addition, the study of women's health in the present thesis was embedded in a psychosocial and developmental context whereby the long-term influence of biological maturation, as well as socio-economic and psychosocial factors related to working conditions and family situation on health development, was specifically explored.

\section{Theoretical framework}

\section{Holistic interactionism}

Traditionally, many of the models and theories attempting to describe the main determinants in general individual functioning and development, including the field of health and disease, have placed an emphasis on unidirectional causal mechanisms. In recent years, however, researchers have become increasingly aware of the need for integrated models and theories characterized by reciprocity, as well as a common framework for their work including a common view of human development 
(Magnusson \& Cairns, 1996). Within this new developmental paradigm, i.e., developmental science, the focus lies in recognizing the fact that individuals function simultaneously as biological, psychological, and social beings. Moreover, individuals are regarded as being purposeful and active in a system of interactions encompassing both themselves and their environment. Within this framework, the individual is seen as an organized whole, whereby every aspect of his/her functioning derives its meaning from the role it plays in the total functioning of the individual and his/her life (Magnusson, 2000).

This perspective implies that reciprocal interactions are seen as taking place between the various sub-systems within the individual; that is, biological, mental, and behavioural, as well as between the individual and the various factors characterizing the environment in which he/she acts (Magnusson, 1988; 1998; 2000; Magnusson \& Stattin, 1996). These mutual, reciprocal influences among the included factors also take place in time, providing the basis for various developmental pathways to evolve. Holistic interactionism can be described by four propositions: a) the totality of the individual; b) the complex and dynamic nature of internal individual functioning; c) the reciprocal interactions among the sub-systems within the individual, as well as between the totality of the internal structure of the individual and the various factors constituting the environment; and d) the changing nature of the environment as a function of the factors involved (Magnusson, 2000).

\section{The person-oriented approach}

Within psychological research it has been common practice to focus on single factors biological, mental or behavioural - of individuals as the main unit of analysis. As such, much research has been conducted on variables and the relations between them. These 
methods are referred to here as variable-oriented. However, it follows from the propositions of the holistic, interactionistic paradigm that it is important to focus on the individual as a totality in relation to the interactions taking place between the studied factors, as well as over time. This ongoing process is seen as lawful and has as its goal to optimize the total functioning of the individual (Magnusson, 1998; 2000). This process is moreover assumed to be characterized by a small number of important factors that operate together, constituting a limited number of typical patterns or configurations, thus reflecting the important properties and their interactions within the system under study (Bergman, 1998; 2000; Bergman \& Magnusson, 1997).

In order to study individuals as totalities and the interactions taking place within the system under study, specific methods have been developed (Bergman, Magnusson, \& El-Khouri, 2003). As their aim is to answer research questions stemming from the propositions of the holistic, interactionistic theory, they are referred to as personoriented. However, they do not exclude the need for the more traditional, variableoriented methods. Rather, these different methods of analysis complement each other, both providing important information. For instance, variable-oriented methods, such as a correlational approach, could serve to give information on which factors are operating within a specific field of study and whether or not they are related to each other - for example, which stress hormones are important in relation to ill health. The next step in increasing our understanding of the role these hormones and various health problems play in the developmental process of poor health might be to use a person-oriented methodology. Doing so, we would get information not only about which factors are important at the group level, but also how they are organized in terms of patterns at the level of the individual. 
Within this context, the studies included in the present thesis applied both variable- and person-oriented methods. In a majority of the studies, however, the analytical unit was variables and the relations between them.

\section{$\underline{\text { Stress and Health }}$}

ag the recent century, biomedical progressions have led to decreasing mortality and morbidity from traditional infectious diseases. At the same time, there have been dramatic changes in society economically as well as socially, especially in western countries. This, in turn, has led to a restructuring of everyday life and psychosocial living conditions that have contributed to increased risks for new lifestyle and stressrelated disorders.

Many of the models linking health and stress have focused on work-related characteristics and conditions of modern working life. Some of the previous researchers within this domain have focused on working conditions such as time pressure, work overload and excessive amount of working hours per week (Starke \& Niedhammer, 2002). However, others have studied stress within theoretically formulated frameworks, although these have primarily been developed from the perspective of working conditions and the balance between work and family life. Below, some of the major stress models linking health and stress are briefly presented.

\section{The biopsychosocial model}

The imbalance between perceived demands in the work environment and the individual's perceived resources to meet those demands forms the basis of the biopsychosocial stress model developed by Frankenhaeuser and colleagues 
(Frankenhaeuser \& Johansson, 1981; Levi, Frankenhaeuser, \& Gardell, 1982). Within this theoretical framework, the imbalance is assumed to be caused by high demands, both quantitatively in terms of a high work pace, too much work to do, or qualitatively, that is, too much responsibility, problems too complex to solve, conflicts, i.e., overstimulation. However, under-stimulation might also cause stress, such as when an individual is not able to use his/her skills, experiences or education, or to develop his/her abilities due to monotonous and repetitive or too-simple tasks (Frankenhaeuser \& Johansson, 1981). Both these conditions are believed to result in feelings of imbalance and thus increase the risk of stress and subsequent health problems and disease.

\section{The Allostatic load model}

McEwen (1998) has proposed a new stress model concentrating on the body's' ability to reach stability through change. By this it is meant that homeostasis, i.e., the stability of physiological systems required to sustain life, is reached by allowing for these systems to adapt to the demands in the environment through change, that is, allostasis (McEwen, 1998; 2003). For instance, catecholamines and cortisol increase during physical and mental activity, resulting in a mobilization of energy stores needed for both the body and the brain during demands and challenges. These adaptations are essential for the body to maintain body temperature and metabolism. Allostatic processes also have more far-reaching effects. For instance, catecholamines and glucocorticosteroids released under stress influence the immune system in terms of facilitating the direction of immune cells to parts of the body where they are needed to build up resistance to an infection (Dhabhar \& McEwen, 1998). Moreover, these hormones work together in the formation of memories of primarily 
dangerous events so they can be recognized and avoided in the future (Roozendaal, 2000).

Thus, allostasis is presumed to support homeostasis, and these processes have a protective effect in the short run. However, if the stress systems are activated for longer periods without rest and recovery, due to environmentally difficult conditions or dysregulated hormone secretion, the result is allostatic overload (McEwen, 1998, McEwen, 2003). This refers to the cumulative cost to the body of maintaining homeostasis through allostasis as an individual adjusts to various demands and environmental changes. In a state of allostatic overload, there are chronic elevations in the secretion of stress hormones like glucocorticosteroids and catecholamines, which might lead to obesity, Type II diabetes, and hypertension (Björntorp \& Rosmond, 2000). High levels of catecholamines also result in making the blood prone to clotting, which is associated with an increased risk for myocardial infarction. Moreover, prolonged periods of elevated blood pressure and heart rate increases the risk for atherosclerosis (McEwen, 1998; McEwen \& Seeman, 1999). Thus, in the long run allostatic overload might lead to pathophysiology in several ways (McEwen, 2003).

\section{The demand-control model}

Karasek (1979) and Karasek and Theorell (1990) have proposed a model of workrelated stress called the job demand-control model. This model has been extensively applied within research on occupational stress and health. It states that psychologically stressful demands in the work environment (time pressure, conflicting demands, mentally difficult and demanding work tasks) - i.e., high job demands - in combination with poor skill discretion and poor decision authority in terms of controllability at work 
- i.e., low decision latitude - results in high job strain. This strain condition defined as high psychological demands and low control was hypothesized to increase the risk for various stress-related diseases such as cardiovascular disease. This hypothesis has been confirmed in several studies (Bosma, Peter, Siegrist, \& Marmot, 1998; Marmot, Ryff, Bumpass, Shipley, \& Marks, 1997; Theorell, 1997). However, mixed findings concerning the health-related effects of this kind of work stress have also been documented. Lately, in splitting the factor of decision latitude, it has been found that skill discretion is more important in predicting health outcomes than is decision authority (Schreurs \& Taris, 1998).

\section{The multiple role hypothesis}

Another stress model that specifically links stressful living conditions most common to women and health outcomes is the multiple role hypothesis. As women often have the main responsibility for household duties and childcare at the same time they are engaged in the labour force, it has been assumed that the responsibilities associated with these multiple roles would lead to role conflict and overload (Sorensen \&Verbrugge, 1987). The effect of this role conflict and overload is in turn assumed to lead to negative health outcomes such as fatigue, exhaustion, and finally disease and mortality (Martikainen, 1995; Sorensen \&Verbrugge, 1987).

However, other perspectives on the health effects of multiple roles have been asserted. The health benefits model states that the advantages related to employment help in maintaining women's health, as they are given a social network, economic independence, and greater confidence in their abilities and decision-making as well as increased self-esteem (Sorensen \& Verbrugge, 1987). Yet another model, the role expansion model, concentrates on the number and type of roles an individual has, and it 
is argued that these multiple roles act together in a synergistic fashion that improves women’s health (Sorensen \& Verbrugge, 1987).

All of the models suggested within the framework of the multiple role hypothesis have been supported in prior research. However, the majority of studies indicate that the role expansion models best explain the health effects of carrying multiple roles. 'Women's health seems to be favoured, rather than damaged, by adding paid employment to their other roles (Hibbard \& Pope, 1991; 1993; Verbrugge, 1986, Vågerö \& Lahelma, 1998).

\section{$\underline{\text { Defining stress }}$}

The concept of stress was first introduced by Cannon in 1935 in his paper "The Stresses and Strains of Homeostasis”, and was later developed by Selye in 1946. He then formulated the General Adaptation Syndrome (GAS), claiming that an individual's relationship with the surrounding environment is a dynamic and ongoing process, as the individual adapts continuously to environmental change (Selye, 1946). Stress was regarded as a non-specific bodily reaction to any significant psychological, physiological or social demand for adaptation (Selye, 1950). Thus, the stress response was considered a reaction to the disruption of the balance between these environmental demands and the resources available to the individual for handling them.

\section{Psychological stress}

Extending on this work, Lazarus presented the theory of coping, suggesting that the coping potentials of an individual, i.e., the ability to handle, and the specific way (strategy) of handling, stressful events and situations - comprised a vital factor in his/her ability to adapt to the perceived demands of a changing environment (Lazarus, 
1966; 1992). The concept of coping has been developed further, suggesting that coping refers to the expectation or ability to master a stressful situation, that is, a positive response to the event in question. In contrast, the expectation of a negative outcome of one's actions has been termed hopelessness, whereas helplessness refers to a state of not expecting any relationship between the resources available to the individual and the results (Ursin, 2000). Moreover, this latter theory aimed at reformulating the classical stress theory within the framework of arousal or activation theory from neurophysiology. Within this perspective, stress is regarded as an alarm signal that is essential to the adaptive system of the body. This alarm in the homeostatic system, i.e. the mechanisms that keep the bodily systems in balance, occurs as a reaction to an imbalance between the expectations of the individual and the actual situation (Ursin, 1988; Levine \& Ursin, 1991). This reformulation of stress theory was labelled the Cognitive Arousal Theory of Stress (CATS). The term "cognitive" referred to the fact that the physiological stress response is activated by an expected outcome of the stressful situation and the available resources. As such, an event must be interpreted as stressful through an individual's specific “coping filter” for the physiological systems to be activated (Ursin, 2000).

Taken together, an individual's perception of internal or environmental demands and the inability to meet these demands are generally seen as the cornerstones in the definition of stress, and the imbalance that the individual experiences due to this determines subsequent psychological and physiological stress responses.

\section{Physiological stress}


In situations that are perceived as stressful, attention is enhanced and the brain focuses on the threat or challenge. The perception of threat is associated with increased arousal, often eliciting a feeling of fear or anxiety followed by physiological reactions. These reactions involve the secretion of stress hormones and activation of the sympathetic division of the autonomic nervous system, leading to increased heart rate, blood pressure and respiration, breakdown of tissue in the mobilization of energy with a redirection of energy to the brain, inhibition of vegetative functions such as sleep, and food consumption as well as various behavioural responses suitable to effectively handle, or cope, with the threatening situation (Meyer, Chrousos, \& Gold, 2001).

There are two major neuroendocrine systems that are considered responsible for the physiological stress response, the sympathetic adrenal-medullary system (SAM) and the hypothalamic-pituitary-adrenal (HPA) axis. These systems are further known to interact multidirectionally with each other, as well as with neural substrates such as the amygdala, the mesolimbic dopaminergic system, and the medial prefrontal cortex (Meyer, Chrousos, \& Gold, 2001). It has been shown that the amygdala mediates anxiety, fear and emotional memory, that the mesolimbic system mediates reward and pleasure, and that the medial prefrontal cortex controls affective and behavioural flexibility (Gold \& Chrousos, 1999). Moreover, these systems interact with the immune system via various pathways (Felten \& Felten, 1994), so that stress also influences immune functions (Abraham, 1991; Maier \& Watkins, 1998).

Although these systems interact, their activities are associated with different aspects of the stress response, and as such have different effects on various bodily systems and functions as well as on behaviour. Thus, in stress research it is common practice to measure different physiological indicators, i.e., neuroendocrine markers, related to the 
activity within these two separate systems (Henry, 1993; McEwen, 1998). These measures of stress indicators have primarily included the catecholamines epinephrine (adrenaline) and norepinephrine (noradrenaline) secreted into the bloodstream when the SAM system is being activated, and the glucocorticosteroid cortisol, secreted by activation of the HPA axis. Other measures involve blood lipids, such as cholesterol, that rise due to increased circulation of catecholamines in the blood, and cardiovascular activity such as heart rate and blood pressure.

\section{The SAM system}

The SAM system is activated when an individual is being challenged in his/her control of the environment and a defence reaction has been developed, as to prepare the body for "fight or flight". This response is regulated by mental influence on the hypothalamus, causing peripheral activation of the adrenal medulla leading to the secretion of the catecholamines epinephrine and norepinephrine into the bloodstream.

There are diurnal variations with high levels in the day, and low levels at sleep (Åkerstedt \& Levi, 1978). The concentration of catecholamines rises in response to stimulation and stressors in less than a minute, and the strength of the response is determined more by the intensity of stress and arousal in general rather than by the emotional quality of stress. Epinephrine has been found to be especially sensitive to mental stress, whereas norepinephrine is released in response to physical activity and body posture, $\stackrel{P}{\underline{\underline{p}}}$ thus, has an important role in the homeostasis of blood pressure (Henry, 1993, Lundberg, 1995).

The catecholamines serve to activate cardiovascular and neuroendocrine functions in ways that mobilize energy to the brain, heart and muscles, whereas it reduces blood 
flow to the internal organs and gastrointestinal system. This activation thus creates a mobilization of energy into the blood, where energy consists of fat from the liver and adipose tissue as well as of glucose (Chrousos \& Gold, 1992; Henry, 1992; Lundberg, 2000; Tsigos \& Chrousos, 2002). The increase in circulating blood lipids includes primarily cholesterol and free fatty acids. Moreover, the cardiovascular changes consist of, for instance, increased blood pressure and heart rate, sustained levels of which might contribute to the development of hypertension, atherosclerosis, myocardial ischemia, and eventually coronary heart disease (Lundberg, 2000). Regarding mental changes due to the output of catecholamines, it has been shown that a slight increase in the catecholamine output taking place under normal conditions is associated with improved mental and cognitive performance. However, during acute and intense stress the high output of catecholamines might lead to mental deterioration and disorganized behaviour (Chrousos \& Gold, 1998; Lundberg, 2000; McEwen, 2000; Tsigos \& Chrousos, 2002).

\section{Assessment of catecholamines}

Blood levels of catecholamines change quickly in response to stress, often within a minute, and a small but constant part of the circulating levels of catecholamines in the blood is excreted into the urine. Thus, assessment of catecholamines can be made from either blood (plasma) or urine, and changes in plasma levels of catecholamine responses to stress have been shown to covary with changes in urine levels. However, plasma catecholamine levels reflect acute responses related to short-term stress, whereas urinary levels represent integrated measures of the stress level covering the time interval between two urine samplings. In the study of longer stress exposure, as in

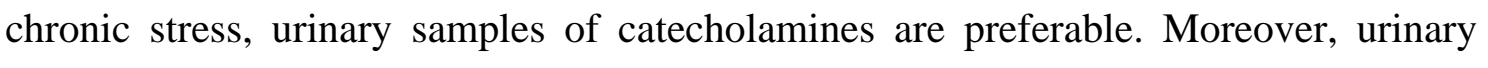
samples are unaffected by confounders such as the stress associated with the blood sampling itself. Also, urinary measurement is easier for the respondents themselves to 
perform in natural settings, such as at the workplace or in the home, without interfering with their activities or habits, and does not cause any pain or harm to the participants. (Lundberg, 2000).

In order to estimate the amount of catecholamine output during a particular period of time, the concentration of the sample is adjusted for by the total urine volume. Thus, the total volume of the sample must be measured after voiding. Moreover, the $\mathrm{pH}$ value of the urine is adjusted to about 3.0 (using acid), to keep the catecholamines from deteriorating. Finally, the acidified urine sample should be kept at -18 C (in a freezer) until being analyzed.

\section{The HPA axis}

The hypothalamo-pituitary-adrenal (HPA) axis is considered responsible for coordinated behaviour, neuroendocrine, autonomic, and immune responses to alterations in homeostasis, and is sensitive to stimuli that threaten homeostasis, i.e., stressors, physiologically or psychologically (Dallman, Bhatnagar, \& Viau, 2000; Tsigos \& Chrousos, 2002). The HPA axis has been found to be especially sensitive to the affective aspects of stress, for instance, feelings of loss of control, anxiety and distress (Kirschbaum \& Hellhammer, 1989; Lundberg, 1995) and is responsible for the secretion of glucocorticosteroids, such as cortisol, from the adrenal cortex (Dallman et al., 2000; Lundberg, 2000), with glucocorticoids playing an important role in energy metabolism and the maintenance of homeostasis (Kollack-Walker, Day, \& Akil, 2000; Tsigos \& Chrousos, 2002).

Normally, cortisol is secreted in a circadian, pulsatile fashion, with a frequency of about two to three bursatile episodes per hour (Chrousos \& Gold, 1998; Tsigos \& Chrousos, 
2002). During rest, the secretory bursts in cortisol increase in the early morning hours, whereas cortisol levels decrease throughout the day, being at their lowest at midnight (Kirschbaum \& Hellhammer, 1998; Åkerstedt \& Levi, 1978). However, during acute stress the episodes (Tsigos \& Chrousos, 1994).

This physiological stress response is necessary for survival of the organism, and has developed to turn on rapidly in response to acute stress. During acute stress, elevated levels of glucocorticoids are useful in helping sustain blood pressure and depress immune function. The rise in glucocorticoids serves to inhibit the immune system in order to limit its scope of attack and thus decreasing the risk that it will attack itself (Kollack-Walker et al., 2000; Tsigos \& Chrousos, 2002). Hence, there is an important feedback loop between the activation of the HPA axis and the following secretion of glucocorticoids, with the immune system with proinflammatory cytokines playing a vital role in this feedback mechanism (Kunz-Ebrecht, Mohamed-Ali, Feldman, Kirschbaum, \& Steptoe, 2003). Once the acute stress has ended, the stress response is shut down again with an ensuing decrease in glucocorticoids, resulting in a normalization of functioning in the systems influenced by the activity of the HPA axis. However, during chronic stress, changes in the response characteristics of the HPA axis seem to occur. The glucocortico-regulatory components inhibit activity in other energydemanding, hormonal systems of the body to mobilize energy stores for "flight or fight" in response to the stressor. This, in turn, leads to a conservation of energy stores needed for immediate use (Dallman et al., 2000). Moreover, as all cell types in the body contain glucocorticoid receptors, chronic corticoidsteroid secretion above normal levels affect the functioning in most tissues of the body, as well as changes in behaviour and endocrine and immune responses (Dallman et al., 2000). Specifically, chronic 
elevations of cortisol, i.e., hypercortisolemia, have been associated with insulin resistance, visceral fat deposition, atherosclerosis, reduced growth, bone loss, and chronic suppression of the mesolimbic dopaminergic system (Chrousos \& Gold, 1999). Taken together, glucocorticoid responses to acute stress are important for maintaining homeostasis, whereas chronic elevations have detrimental effects on the organism, leading to the development of ill health and various diseases.

\section{Assessment of cortisol}

Cortisol is excreted into the bloodstream with a small fraction going into the urine, as with catecholamines. Thus, cortisol can be measured in both plasma and urinary samples. However, cortisol is also excreted from the blood into saliva, thus the hormone levels can be determined via measurement of saliva cortisol. The validity of this measure is evidenced from studies showing high associations between cortisol levels in blood, urine and saliva. Moreover, saliva cortisol measures are regarded as being less stressful to participants than is blood sampling, and are associated with less interference in the activities of their daily lives than are both blood and urinary sampling (Lundberg, 1995; 2000).

Salivary cortisol is most commonly measured using the "Salivette" (Sarstedt Inc., Rommelsdorf), a sterilized cotton swab in a plastic tube. The swab is put in the mouth and chewed for about 120 seconds to ensure collection of the amount of saliva needed to assess cortisol. The samples can be stored at room temperature for a couple of weeks, but need to be frozen if stored for a longer period of time.

In assessing catecholamines, as well as cortisol, it is important to take circadian rhythms, individual differences, potential influences of tobacco use, alcohol, caffeine, 
and medicines into consideration. In order to take account of the circadian rhythm in cortisol, frequent sampling is necessary. Moreover, there are large individual differences in both catecholamines and cortisol. Therefore, the most appropriate method of measurement is to compare rest (baseline) and stress levels at the same time of day. In addition, participants are asked not to smoke or drink coffee or alcohol, or are advised to consume similar amounts across the measurement sessions. The effects of these factors are either held constant or controlled for (Kirschbaum \& Hellhammer, 1989; Lundberg, 1995; 2000).

\section{Defining health}

The World Health Organization has defined health as "a state of complete physical, mental and social well-being, and not merely the absence of disease or infirmity" (WHO, 1948, p. 28). The perspective adopted by WHO includes the western traditional view of health as the absence of disease, whereby health and disease are established according to objective criteria. Within this perspective, health is generally seen as the removal of symptoms and diseases or the prevention of their occurrence. Thus, in the traditional biomedical model there has been a focus on ill health and disease from a primarily physiological perspective, whereby diagnoses are based on organic dysfunction and tissue damage, and a purely medical etiology can be stated. However, a large proportion of diseases, particularly the lifestyle and stress-related disorders of modern society, are not explained by structural abnormalities. Instead, psychosocial and biological pre-determinants are seen as interacting in the expression of illness and disease. Therefore, the traditional model has become insufficient in its explanations,

and has gradually been replaced by a biopsychosocial perspective focusing on the 
interaction between biological, psychological, and social factors in the development of health problems and disease.

Returning to the definition stated by WHO, it also includes a subjective perspective on health, focusing on people's feelings of being well or ill. This perspective is characterized by a holistic view of the individual whereby individuals are seen as totalities. The holistic perspective is dynamic in the sense that the continuous changes of individuals' life conditions are thought to affect health and the quality of life (Kalkas, 1990; Magnusson, 1988; 1998). The latter perspective reflects the individual's perception of his/her health state, and it is increasingly accepted as an important aspect of health.

In view of the definition stated by WHO, health could be regarded as a complex multidimensional concept, and one of the important factors in the study of individuals' health development is the subjective component. This component is usually referred to as perceived, self-assessed, self-evaluated, self-reported or self-rated health (Björner, Söndergaard-Kristensen, Orth-Gomér, Tibblin, Sullivan, \& Westerholm, 1996).

\section{Self-rated health}

Self-rated health (SRH) is thought of as being the individual's general perceptions and evaluations of his/her health, and has been defined as an individual's perception of his/her symptoms, well being, general health and vulnerability (Björner et al., 1996). From this definition it follows that the concept of SRH is distinguished from both medical health and functional ability. As previously stated, medical health has been defined in accordance with a biomedical model whereby the absence of definable 
disease is the basic criterion of health. Functional ability, on the other hand, represents a social definition of health - i.e., the ability to perform various tasks and roles within a social context (Liang, 1986).

In previous research, SRH has been found to be a stronger predictor of future morbidity and mortality than are medical diagnoses (Appels, Bosma, Grabauskas, Gostautas, \& Sturmans, 1996; Helmer, Barberger-Gateau, Letenneur, \& Dartigues, 1999; Idler \& Angel, 1990; Idler \& Benyamini, 1997; Jylhä, Guralnik, Ferrucci, Jokela, \& Heikkinen, 1998; Moller; Kristensen, \& Hollnagel, 1996; and Yu, Kean, Slymen, Liu, \& Katzman, 1998), and more stable than medical evaluations of health as well (Goldstein, Siegel, \& Boyer, 1984; Miilunpalo, Vouri, Oja, Pasanen, \& Urponen, 1997; Rodin \& McAvay, 1992). One possible explanation for this stability might be that people make distinguish between the doctor's diagnosis and their own explanation of their symptoms (Hunt, Jordan, \& Irwin, 1989). It has been argued that the perception and interpretation of various symptoms and their causes may differ between the layperson and the biomedical models of etiology and pathogenesis (Schober \& Lacroix, 1991), and as such, physician information is only one component in patients' understanding of their symptoms. In addition, it has been found that SRH is a strong predictor of health care use for a number of different diagnoses (Undén \& Elofsson, 1998; Weinberger, Darnell, Tierny, Martz, Hiner, Barker, \& Neill, 1986), as well as for hospitalization (Wan, 1976).

As most previous research has been cross-sectional, it is not possible to draw conclusions of the causal directions between SRH and other related factors. However, in the few studies that have used a longitudinal design, the factors associated with SRH are the same as in cross-sectional studies, and SRH also seems to be very stable over 
the years (Idler, 1993; Johnson, Stallones, Garrity, \& Marx, 1991; Maddox \& Douglass, 1973; Rodin \& McAvay, 1992).

There are consistent results across studies showing that the experience of not feeling well has an association to future morbidity and mortality in both men and women, and in different age groups. Factors found to be associated with SRH are bodily pain, chronic medically defined morbidity, $\stackrel{-\rho}{\equiv}$ ical functioning, symptoms from the musculoskeletal system, depression and anxiety, as well as socio-economic problems and lifestyle factors such as low income, short education, repetitive work, job strain, and smoking (Borg \& Kristensen, 2000; Fylkesnes \& Forde, 1991; Heidrich, 1993; Kawachi, Kennedy, \& Glass, 1999; Kempen, Jelicic, \& Ormel, 1998; Kivinen, Halonen, Eronen, \& Nissinen, 1998; Leibson, Garrard, Nitz, Waller, Indritz, Jackson, Rolnick \& Luepke, 1999; Ratner, Johnson, \& Jeffery, 1998).

In examining individuals’ perceptions of what health means, it primarily concerns the absence of illness but also has connections to personal experiences and life situation (Manderbacka, 1998). However, the contribution of health behaviours to SRH has been found to be low. Instead, their effect on SRH seems to be mediated by more specific health problems and their functional consequences (Manderbacka, Lundberg, \& Martikainen, 1999).

The arguments against SRH measures as indicators of health points to the fact that selfreports of symptoms are prone to errors as many symptom perceptions are based upon internal stimuli without any physical, objective referent (Cacioppo, Andersen, Turnquist, \& Tassinary, 1989). But if one is interested in measuring health as an individual experience, and not only as the absence or presence of medical symptoms 
and diseases, or comparing self-reports of health with physician-reports based on medical examinations, then the individual is likely the most suitable person to judge his/her own state of health (Manderbacka, 1998). Thus, medical health and SRH should be regarded as two different, but complementary, perspectives on health whereby each is useful for specific purposes (Björner et al., 1996).

\section{Measuring self-rated health}

Measures of SRH have been designed in mainly three different ways: global noncomparative SRH, global age-comparative SRH, and global time-comparative SRH.

The non-comparative measure consists of one question such as "How would you assess your own health condition?" or "How would you rate your own health at present?". Most studies have used the response categories excellent, good, fair, poor, and very poor, and only a few have used an age-comparative measure of SRH. The questions used have been "What do you think of your own health condition compared to that of other men/women of your age?" or "Do you think your health is good/fair/poor for your age?". The theoretical assumption behind the age-comparing measure is that individuals make health status comparisons to other people of their own age. An example of the time-comparative measure is " Compared to one year ago, how would you rate your health in general now?" (Undén \& Elofsson, 1998).

Somewhat contradictory results have emerged between studies using the various SRH measures, indicating that different background factors such as different frames of reference could be operating (Undén \& Elofsson, 1998). For instance, the agecomparative question has been shown to favour groups of older respondents compared to younger ones, while the global health question has been found to have the reverse

effect (Roberts, 1999). That is, older respondents rate their health as better than 
younger ones do when answering the age-comparative question, whereas younger respondents report better health than older people do with the global health question.

The basic idea in all SRH measures is that people compare their health status with some standard or norm, and that this standard may change under certain circumstances. The problem is that one does not truly know how people make comparisons or what frame of reference they use. People may feel healthy in one respect but ill in another, which makes it difficult to give a global health rating (Jylhä, 1994). So, when people are to interpret and answer global self-ratings of health they may use different frames of reference, whereby the specific referents may vary with age or between people who are medically healthy and those who have a serious disease (Krause \& Jay, 1994).

This phenomenon is explained partly by social comparison theory, which states that people’s judgements about the severeness of symptoms depend upon which reference, or comparison group, they choose. For instance, it has been shown that people are inclined to make downward comparisons, i.e., making evaluations of one’s health by using other people with worse health than one's own as frames of reference, in order to maintain a positive self image (Breetvelt \& van Dam, 1991).

\section{Self-reported symptoms}

Another, and to this date perhaps the most common, way of measuring subjective health status is by self-reported physical and mental symptoms. This measure of health might be considered to be more objective than SRH as it asks respondents to report which symptoms they have experienced during a specified time period, how often, and occasionally how severe they have been. Hence, individuals are expected to be able to 
report their health state more specifically in terms of whether they have or have not had, for instance, headaches or stomach problems during the past month.

Commonly reported symptoms in health surveys and in the primary health-care setting mainly concern gastrointestinal problems, headaches, musculoskeletal pain, sleeping difficulties and mental problems such as worry, nervousness and sadness (Krantz \& Östergren, 1999; Ursin, 1997). In most cases, no medical etiology or organic dysfunction can be found, and it is not possible to state a medical diagnosis (Malterud, 1987a; 1987b). Hence, these symptoms have been referred to in the literature as medically unexplained symptoms or subjective health complaints (Ursin, 1997, 1998, 2000).

\section{Gender differences in symptom reporting}

There is a vast body of research showing that women are overrepresented in symptom reporting as compared to men (Gijsbers van Wijk, Kolk, van den Bosch, \& van den Hoogen, 1995; Gijsbers van Wijk \& Kolk, 1997; Hall, 1992; Malterud, 1987a; Malterud, 1987b; Tibblin, Bengtsson, Furunäs, \& Lapidus, 1990). In the context of these earlier findings it has been hypothesized that women might be more sensitive to bodily discomfort, have a lower pain threshold, be more attentive to bodily sensations, and be more willing to report symptoms in health surveys and to discuss health problems, and it is claimed this is due to the socialisation process of gender, that is, the different behaviours and attitudes that girls and boys are met with during their upbringing. (Verbrugge, 1982; 1983; 1985; Verbrugge \& Wingard, 1987). These behaviours are furthermore presumed to influence coping strategies and the sensitivity to illness (Hammarström, 1996). However, this higher prevalence of symptom reporting among women has also been found to reflect more actual somatic and mental symptoms 
as compared to men, and not to simply be the effects of socialisation or a tendency toward bodily introspection and attention (Gijsbers van Wijk et al., 1995; 1997; Malterud, 1987a; 1987b; Tibblin et al., 1990). In addition, the roles ascribed to women and their subsequent demands in terms of being in the paid work force and simultaneously having the main domestic responsibility are assumed to be responsible for a large proportion of the higher prevalence of symptom reporting among women (Gore \& Mangione, 1983; Popay, 1993; Rosenfield, 1989).

Although there is strong evidence for this overrepresentation of female symptom reporting as compared to men, some studies contradict this widely held view. For instance, Macintyre and colleagues found no gender differences in symptom reporting (1999). One possible explanation for these contradicting results could be that women report more mental symptoms as well as more unspecific, medically unexplained symptoms, whereas men report more serious $\underline{\underline{\underline{\beta}}}$ is conditions that are more infrequent (Macintyre, Hunt, \& Sweeting, 1996).

\section{Somatisation}

When the vague and medically unexplained symptoms described above are pronounced, they qualify for the clinically stated diagnosis of somatisation disorder in the Diagnostic and Statistical Manual for mental disorders (DSM IV, 1994). The primary feature of somatisation disorder is the persistent presence of physical symptoms that points to a medical condition but where no general medical condition can account for the physical symptoms. Thus, the disorder is assumed to include substantial psychological elements rather than being due to any actual medical condition. The complete criteria for receiving a diagnosis are very strong and the prevalence of somatisation disorder ranges from $0.2 \%$ to $2.0 \%$ among women and is less than $0.2 \%$ in 
men. When the symptoms are less pronounced, they might be classified within a residual category for other persistent somatoform manifestations that do not meet the full criteria for somatisation disorder, termed undifferentiated somatoform disorder. It is assumed that these symptoms constitute general distress employed to express concern about various personal or social problems, although this does not necessarily co-occur with any psychopathology (DSM IV, 1994). However, the reports and prevalence of symptoms and health complaints in the general population seldom meet the criteria for any of the above disorders, and as such "only” reflect commonly reported, medically unexplained symptoms.

\section{Somatic interpretation and attribution theory}

Identification of a bodily sensation as a symptom requires an interpretation of the sensation in question. This feature of organising information in a structured, meaningful way is characteristic for humans. In order to understand and get useful information about events we need to correctly interpret what is happening in the environment. To do this we try to find meaningful relationships between occurrences, form coherent pictures of their nature, and develop causal theories about them (Bohner, Bless, Schwartz, \& Strack, 1988). On the basis of attribution theory, it has been assumed that attributions made for somatic sensations take place and are organised within larger schemata of the world, including our bodily-biological world. In this way, illness schemata are cognitive structures that both organize and represent our previous experience and knowledge about health and disease. These illness representations guide the collection and interpretation of somatic and medical information, which in turn are used to make interpretations and inferences about symptoms, and also function as a set of expectations for the encoding of new information (Leventhal \& Diefenbach, 1991). Thus, from a cognitive perspective on symptom perception it is argued that perceptual 
stimuli from bodily organs interact with pre-existing illness schemata based on previous experience and/or knowledge. Moreover, somatic interpretation is viewed as being influenced by the situation, behaviour of others, and the beliefs, assumptions, and attitudes of the perceiver (Cioffi, 1991).

\section{Sensitization}

Another possible explanation for medically unexplained symptoms stems from psychobiology, proposing that sustained activity within psychobiological loops might lead to a heightened sensitivity in neuronal chains. When a neuronal chain is exposed to repeated use, the synaptic efficiency in that chain increases. This would in turn affect the development of an increase in somatic complaints as the sustained activity lowers sensory thresholds for various symptoms (Ursin, 2000). This view is supported by findings showing that patients with different symptoms have lower thresholds for stimuli related to their specific symptoms. For instance, patients with stomach problems are more sensitive to gut stimuli than are others, whereas patients with muscle pain have lower thresholds for muscle pain than do healthy individuals (Ursin, 2000). Moreover, cognitive models of sensitization have also been developed, suggesting that strongly felt concerns, such as fears, might elicit a cognitive-emotional sensitization. This kind of psychological sensitization is assumed to be present in the context of bodily information related to illness, and long-term rumination, worry, and negative affect have been suggested as catalysts in the development and maintenance of medically unexplained symptoms (Brosschot, 2002).

\section{Symptom reporting and personality}

When studying self-reported somatic complaints in relation to personality, factors such as hypochondria and somatisation (Barsky, Cleary, \& Klerman, 1992), neuroticism 
(Costa \& McCrae, 1985), and negative affectivity (Watson \& Pennebaker, 1989, Gijsbers van Wijk, Huisman, \& Kolk, 1999) have been associated with symptom reporting. Hence, a combination of certain personality factors related to symptom reporting has been referred to as a tendency toward psychological vulnerability, and these factors include worry and anxiety, negative affectivity, neuroticism, and hostility (Spinhoven, Jochems, Linssen, \& Bogaards, 1991; Vassend, 1987, 1989).

\section{Biological maturation}

A research area related to symptom reporting is the topic of biological maturation, also called pubertal timing (Caspi, Lynam, \& Moffitt, 1993; Ge, Conger, \& Elder, 1996; Ge, Conger, \& Elder, 2001; Graber \& Brooks-Gunn, 1996; Graber, Lewinsohn, Seeley, \& Brooks-Gunn, 1997; Petersen, Sirigiani, \& Kennedy, 1991; Rierdan \& Koff, 1991; Stattin \& Magnusson, 1990; Stice, Presnell, \& Bearman, 2001; Susman, Dorn, \& Chrousos, 1991). This implies the time when an individual leaves childhood and enters adolescence. This period of development is characterized by change in several areas, such as cognitive, social, emotional and physical (Forman, 1993). The adaptational process to meet the new challenges and demands placed upon the individual is assumed to lead to increased stress (Seiffge-Krenke, 1995), which in turn has an impact on health (Simmons, Burgeson, \& Charlton-Ford, 1987). In this context, the timing of transition into adolescence, i.e., biological maturation, is believed to be of importance for adjustment within several domains, as it is presumed to influence how individuals experience and negotiate with such transition (Graber \& Brooks-Gunn, 1996). In particular, it has been hypothesized that experiencing this transition earlier than other adolescents is a potential risk factor for non-successful adaptation. The reason for this would be that the adolescent has less time than others do to learn the necessary skills 
for an appropriate way of handling the new situations with which he or she is faced (Graber \& Brooks-Gunn, 1996; Stattin \& Magnusson, 1990).

Prior research has indeed supported this hypothesis, showing that the risk associated with early biological maturation is especially pronounced among girls. Early-maturing girls have been found to $\mathrm{ft}$ higher levels of symptom reporting as well as to have more externalizing problem viours in adolescence than girls with normal or late biological maturation (Aro \& Taipale, 1987; Bergman \& Wångby, 1995; Caspi et al., 1993; Ge et al., 2001; Graber et al., 1997; Petersen et al, 1991; Rierdan \& Koff, 1991; Stattin \& Magnusson, 1990; Stice et al., 2001, Susman et al., 1991). However, there is a gap in knowledge regarding the impact of the possible timing of biological maturation on health development into adulthood.

\section{Gender research}

Gender refers to the positions or roles that women and men occupy in society, whereas sex refers to their biological characteristics. Thus, gender is regarded as a socio-cultural construct that differs between various cultures and societies, and that changes over time, while biological characteristics are universal. As gender is a socio-cultural construct, it is developed and maintained by the socialisation process, which in turn gives rise to the development of behaviour patterns in line with gender-specific expectations (Harding, 1986; Hirdman, 1988).

Gender research is a relatively new scientific discipline with the purpose of bringing forth issues focusing on the division of power within societal structures, where the gender order in society is seen as one base for the division of labour, resources, and 
control. The imbalance of power has traditionally favoured men, whereas women have been disadvantaged. This has also been the case in science, with a large proportion of prior research being based on the study of men - mainly white, middle-class, heterosexual men - leading to what has been labelled the male norm. This norm has been criticised for representing inequities within the societal structures in a hierarchical fashion, where men are seen as the standard for what is normal and valid (Hammarström, 2002).

In medical research this has been manifested in women traditionally being excluded from medical studies (Hammarström, 1991; Puranen, 1994). For instance, studies on coronary heart disease, stroke, ulcer, and hypertension have been conducted mainly on men (Hammarström, 1991). One result of this imbalance in medical research is that 'women's symptoms and disorders have often been difficult to classify as women do not $\stackrel{P}{\underline{\underline{P}}}$ ent with the same symptom patterns as men do in various medical conditions, which in turn has affected the treatment given to women. The contribution of gender research in this area has resulted in increased knowledge and understanding of diseases more common among women than men, such as fibromyalgia, chronic pain and musculoskeletal disorders. Moreover, it has been shown that the study of these disorders often receives small resources in traditional research (Hammarström, 2002). In view of the previously neglected study of women's health and specific living conditions as contrasted with the strong overrepresentation of symptom reporting and health problems among women, the importance of studying individual differences among women, instead of viewing them as a homogenous group being compared with men, becomes vital. 
Drawing on gender theories of differences in health between women and men, Gijsbers van Wijk and Kolk (1997) presented a symptom perception theory that regards symptom reporting as a multi-causal phenomenon. According to their model, the excess in symptom reporting among women could be explained by a perceived excess of somatic information due to the female reproductive role, a general tendency to attend selectively to bodily cues, a stronger tendency to somatise among women as compared to men as well as greater willingness to report symptom experiences, and importantly, the disadvantageous social position of women. This model supports the notion that women's living conditions influence their higher rates of symptoms, and as such, mirror general distress and psychosocial stress.

The present thesis concerns women's health in Sweden between the years 1970 and 1998 from a developmental and psychosocial perspective. Although traditional gender research compares men's and women's living conditions and the power relations between the two sexes presumed to be reflected by these conditions, studies on only one sex are also regarded as gender research when the gender differences are already investigated and well-known.

\section{Specific aims of the thesis}

To explore the agreement between self- and physician-ratings of general health status (SRH and PRH) among 43-year-old women, as well as the potential power of

self-reported symptoms and diseases, and physician-reported health problems in predicting both SRH and PRH. 
To investigate individual as well as structural stability in symptom reporting among females over time, as related to biological maturation, using person-oriented methodology.

To test the hypothesis that poor socio-economic and psychosocial conditions predict a high level of common symptoms and poor self-rated health (SRH) among 43-yearold women, longitudinally as well as cross-sectionally.

To test the hypothesis that a high level of common symptoms among 43-year-old women is associated with elevated levels of physiological stress responses.

\section{Study population and setting}

Females representing the general population in a middle-sized urban Swedish community included in the longitudinal IDA programme (Individual Development and Adaptation; Bergman, 2000; Magnusson, 1988; Magnusson \& Bergman, 1997) constituted the study samples in the papers included in this thesis. The IDA programme encompasses all children attending the third grade in the town of Örebro during the 1964/65 school year. Children who moved into the region and became classmates with those constituting the original sample were also included in the programme. In Sweden, children in Grade 3 are normally 10 years old, and most of the children in the study cohort (89\%) were born in 1955. The main group was comprised of 683 girls in 1965. This cohort has been followed to adult age. 
During the last data collection in 1998, when the women were approximately 43 years of age, 488 women (of the remaining main group of 569, response rate $85.7 \%$ ) filled in a health questionnaire covering 19 commonly reported physical and mental symptoms in the general female population (Krantz \& Östergren, 1999; Tibblin et al., 1991), as well as a checklist consisting of common diseases. All the listed symptoms and diseases were included in the subsequent analyses. The women were also asked to rate their own general health status (SRH). For 369 of these women, a routine medical examination was carried out. The physicians rated the general health status (physician rated health = PRH) of the women, as well as current health problems, on a medical checklist.

\section{$\underline{\text { Study II }}$}

Data collected when the females were 15 years of age formed the basis for Study II. At this time, the girls answered a symptom checklist covering physical and mental symptoms common among female adolescents (Craaford, 1972; Wångby, Stattin, \& Magnusson, 2002) as well as a question on when they had their first menarche. As the study focus was on symptom reporting in relation to biological maturation, i.e., timing of menarche, chronological age was eliminated as a possible confounder by only including girls born in 1955 ( $\mathrm{n}=590)$. There was complete information on the studied symptom variables (headaches, stomach problems, sleeping difficulties, and sadness) for 477 of these females, thus forming the study sample at age 15. During the data collection conducted in 1998, the women filled in the previously mentioned health questionnaire covering commonly reported physical and mental symptoms in the general female population. The study sample at age 43 included 438 women, for which there was complete data in the same symptom variables as at age 15 . The longitudinal sample used for studying stability in symptom reporting over time comprised 352 women, for whom there was complete symptom data at both ages 15 and 43 . 


\section{$\underline{\text { Study III }}$}

In 1981 and 1998, when the women were 26 and 43 years of age, respectively, new data collections were conducted (age $26 n=577$ females, and age $43 n=569$, participation rate $89.9-90.0 \%)$. At both times, questionnaire data on socio-economic and demographic factors were collected. At age 43, self-report measures of job strain, income, financial worries, unpaid household work, self-rated general health (SRH) and common symptoms were added. A symptom index was constructed, including eight symptoms that were reported by more than ten percent of the study population (Cronbach’s alpha 0.76). The included symptoms were neck/shoulder pain, back pain, stomach problems, tiredness/fatigue, rashes/skin problems, difficulty relaxing, headaches, and sleep disturbances. As there was no information on health status at age 26, the same symptoms included in the person-oriented analyses in Study II from age 15 (headaches, stomach problems, and sleeping difficulties) were summated (symptom index with Cronbach’s alpha 0.61) and included in Study III as well, in order to control for their possible effect on symptom reporting and SRH at age 43.

\section{$\underline{\text { Study IV }}$}

Cross-sectional data from 1998, when the women were 43 years of age, were used. A small but representative subsample of women was included. The sample consisted of 222 women for which there were complete data on the catecholamines epinephrine (E) and norepinephrine (NE), as well as on cortisol. Data for these 222 women were also taken from the routine medical examination, and in the study measures of blood pressure, heart rate, height, weight, and blood lipids such as cholesterol were included. Moreover, the women filled in the previously described symptom checklist covering 
common physical and mental symptoms. An index covering the ten most commonly reported symptoms was constructed (Cronbach’s alpha 0.79). This index differed from that used in Study III in that it also included two mental symptoms, sadness and nervousness, that were reported just below the ten-percent limit used as a cut-off point in Study III.

\section{Statistical methods}

\section{Study I}

Cohen's kappa was calculated for the agreement between the women's own health ratings (SRH) and the physicians' ratings (PRH). Due to skewed distributions, Spearman's rank order correlations were computed between SRH, PRH, self-reported symptoms and diseases, as well as physician-rated health problems. However, the Spearman coefficients showed only minor disparities from the Pearson type correlation. Inter-relations between symptoms, diseases and health problems were also computed with rank order correlations. Multiple logistic regression analyses were carried out in order to determine the relative role of the variables in predicting SRH and PRH. Sum scores of symptoms, diseases and health problems were used as independent variables, and SRH and PRH served as dependent variables in separate analyses.

\section{$\underline{\text { Study II }}$}

Bivariate Pearson correlations were calculated between the symptoms studied, crosssectionally at both ages 15 and 43, as well as longitudinally. Moreover, correlations were computed between symptoms at both ages 15 and 43, and timing of menarche. Cluster analyses using Ward's method were carried out on the age 15 and the age 43 samples. The obtained cluster solutions from the two time points were cross-tabulated with timing of menarche, as well as with each other, in order to analyse observed and 
expected frequencies in the patterns of symptom frequencies as related to timing of menarche, and over time.

\section{$\underline{\text { Study III }}$}

Odds ratios (OR) and 95\% confidence intervals were used to estimate the bivariate associations between demographic, socio-economic and psychosocial variables at ages 26 and 43, and self-reported symptoms and SRH at age 43. Multiple logistic regression analyses were carried out to identify the statistically independent risk factors predicting a high level of common symptoms and poor SRH, adjusting for symptom reporting at age 15. The variables that showed the strongest associations with a high level of symptoms and poor SRH were tried as potential confounding factors. As education at ages 26 and 43 was highly correlated $(r=0.78) ~$ were not included in the same model. Instead, education at age 26 was chosen in order to emphasize the longitudinal perspective. Moreover, job strain and unemployment were investigated in separate analyses. To estimate the effect of combined exposure, i.e., having a heavy domestic workload and simultaneously being in a job strain situation, a multivariate analysis was performed with the combined variable "combined exposure". To test for effect modification, a synergy index (Rothman, 1986) was analysed, whereby the two exposures in combination are presumed to enhance the risk for a specific outcome, which in Study III concerns a high level of common symptoms and poor SRH.

\section{Study IV}

The symptom index constructed for this study was divided into three groups of approximately the same size representing a high, intermediate, and low symptom load. T-tests were carried out in order to investigate possible differences between the 
symptom groups regarding stress responses in catecholamines and cortisol, as well as physiological health measures based on medical examinations.

\section{The empirical studies}

\section{Study I Self- and physician-rated general health in relation to symptoms and diseases among women.}

\section{Background}

Previous international research has shown that women consistently report worse health than men do in terms of a higher prevalence of physical and mental symptoms (Gijsbers van Wijk et al., 1995; Gijsbers van Wijk \& Kolk, 1997). The same trend is also found in Sweden (Hall, 1992; Malterud 1987a; 1987b; Tibblin et al., 1990), long-term sick- and disability leave to a higher extent than do men (RFV, 2002). Moreover, it has also been shown that poor self-rated health (SRH) is more strongly related to, and a better predictor of, future morbidity and mortality than are medical diagnoses (Appels et al., 1996; Helmer et al., 1999; Idler \& Benyamini, 1997; Idler \& Angel, 1990; Jylhä et al., 1998; Moller et al., 1996; Yu et al., 1998), as well as health care utilization (Warren, 1994), whereas the determinants of SRH are less clear.

\section{Aim}

As women report more health problems than men do, and are more frequent visitors within the primary health-care setting, and as physicians are those who meet with these women, decide on tests to be performed as well as treatment and medication, state diagnoses, and make decisions on sick- and disability-leave, it was considered 
important to study the association between middle-aged women's self-reported symptoms and medical evaluations of their health. Moreover, the potential power of women's self-reported symptoms as well as physician-rated health problems in predicting general health in terms of SRH and physician-rated general health status (PRH) was investigated.

\section{Results}

Findings indicated a high degree of agreement between the general health ratings by the women and those by the physicians $(p<.001)$, although the measurement of agreement (kappa) only reached 22\% due to skewed distributions with the majority of the health ratings stating good general health status. However, approximately twice as many women were rated by the physicians as having poor health, compared to vomen's own ratings. There were significant associations between all the self-reported symptoms, as well as between many of the self-reported diseases, pointing to a high degree of co-morbidity. Moreover, logistic regression analyses showed that only selfreported symptoms predicted SRH $(24 \%$ explained variance, $p<.001)$. In this context, it was found that the mental symptom "a sense of powerlessness" contributed to $20 \%$ of the variance in SRH. In addition, both self-reported symptoms and physician-rated health problems predicted PRH (13\%, and 11\% explained variance, respectively, $p<$ .001). Notably, self-reported diseases failed to predict both SRH and PRH.

\section{Conclusion}

There was a high agreement in making health ratings between the women themselves and the physicians. However, general health status was only partly predicted by symptoms and medically examined conditions. Thus, evaluations of general health 
seem to include other factors not only related to the absence or presence of symptoms and current health problems.

\section{Study II Symptom development and timing of menarche: A longitudinal study.}

\section{Background}

Due to the high symptom prevalence among adult women (Gijsbers van Wijk et al., 1995; Gijsbers van Wijk \& Kolk, 1997; Malterud, 1987a; 1987b; Krantz \& Östergren, 1999; Tibblin et al., 1991), it was considered important to investigate the development of symptom reporting among females from adolescence to middle-age.

\section{Aim}

Our purpose was to gain an understanding of the stability and/or change in symptom reporting over time, both for the individual female as well as at the structural level, that is, how the studied symptoms tend to organize themselves in patterns. In order to do this, both a variable-oriented and a person-oriented methodology were applied. Moreover, as biological maturation has been found to influence symptom reporting during adolescence (Aro \& Taipale, 1987; Bergman \& Wångby, 1995; Caspi et al., 1993; Ge et al., 2001; Graber et al., 1997; Petersen et al, 1991; Rierdan \& Koff, 1991; Stattin \& Magnusson, 1990; Stice et al., 2001, Susman et al., 1991), we included this factor in order to also answer the question of whether it exerts a long-term influence on symptom reporting.

Results 
Symptoms for which there was corresponding information at both ages 15 and 43 were included in the study. These were headaches, stomach problems, sleeping difficulties, and sadness. The results showed that all the included symptoms were related with each other at both ages. Moreover, there was longitudinal correlational stability between all of the symptoms. Thus, the findings revealed that the studied symptoms were related to each other at the group level based on the total sample mean. In addition, girls with an early menarcheal timing had a high frequency of symptoms at the age of 15, whereas no significant correlation was found between early menarche and symptom reporting at age 43. Secondly, the results showed structural as well as individual stability over nearly thirty years. That is, similar patterns of symptoms emerged at both ages 15 and 43, and it was the same females reporting either a high or low symptom load at both ages. Moreover, at age 15 more girls with late menarche than expected by chance, and fewer of the early-maturing girls than expected by chance, reported being symptomfree, whereas this was not the case at age 43.

\section{Conclusion}

There seems to be an influence of early biological maturation on symptom reporting in adolescence, as found in previous research. However, this effect does not extend into adulthood. Instead, it seems to be the experience of symptoms in adolescence per se that puts females at risk for developing future poor health. It is noteworthy, however, that this kind of individual stability was found for only a small number of females with high symptom frequencies already in adolescence. 


\section{Study III Psychosocial conditions and self-reported health among women. A longitudinal study.}

\section{Background}

On the basis of the results from both Studies I and II, there was an interest in trying to identify other possible factors operating in the process of health development among females. The two previous studies focused on symptom reporting in terms of its possible stability and/or change over time, as well as its power in predicting SRH and PRH. However, the predictive power of self-reported symptoms in relation to SRH and PRH was quite low (Study I), and in Study II we investigated symptom development solely in relation to biological maturation, which showed an effect only in adolescence.

\section{Aim}

Thus, Study III aimed at exploring both the possible long-term and short-term effects on health in relation to certain living conditions, emphasizing the disadvantageous position of women assumed to be detrimental to their health development. The study was specifically aimed at investigating whether demographic and socio-economic and factors in young adulthood predicted poor self-reported health in middle age, and moreover, studied the extent to which contemporary psychosocial life circumstances in middle-age were associated with poor health.

\section{Results}

It was found that job strain $(\mathrm{OR}=1.86 ; 1.09-3.17)$, and financial worries $(\mathrm{OR}=2.31$; 1.32-4.03 ge 43 predicted a high level of symptoms at age 43. Moreover, poor SRH at age 43 was predicted by low income $(\mathrm{OR}=2.08 ; 1.12-3.84)$, job strain $(\mathrm{OR}=2.67$; 1.21-4.25) and financial worries $(\mathrm{OR}=2.36 ; 1.22-4.56)$ at age 43. The results also 
showed that for the women in a double-burden situation, there was an increased risk for both a high level of symptoms $(\mathrm{OR}=2.80 ; 1.34-5.86)$ and poor SRH $(\mathrm{OR}=3.03$; 1.34 6.88). To test for effect modification, a synergy index was calculated and showed 1.75 for symptom reporting and 1.30 for poor SRH, indicating a synergistic effect on both health measures.

\section{Conclusion}

It was concluded that it is current, work-related psychosocial conditions leading to poor SRH and a high level of common symptoms among middle-aged women. In particular, a high total workload in terms of high job strain at work and heavy domestic responsibilities increased the risk for poor self-reported health.

\section{Study IV Medically unexplained symptoms in women as related to physiological stress responses.}

\section{Background}

The main results from Study III showed that poor contemporary psychosocial conditions in terms of job strain, low income, financial worries and double burden predicted poor self-reported health among women at age 43. Poor health was defined as both a high level of common, medically unexplained symptoms and poor SRH.

\section{Aim}

As we previously found that poor psychosocial conditions predicted a high level of symptoms (Study III), which was interpreted as reflecting psychosocial stress, we now wanted to explore whether common self-reported symptoms were associated with physiological stress responses among middle-aged women. 
Results

The findings showed that women reporting a high level of common symptoms had significantly higher heart rate $(t(2.2 ; \mathrm{df} 135.5) p<.05)$ and total cholesterol $(t(1.9 ; \mathrm{df}$ 114.3) $p<.05$ ) as compared to women with an intermediate symptom load. In addition, women reporting a moderate symptom load had significantly higher cortisol levels than those belonging to the low symptom load group ( $t(2.3$; df 41.2$) p<.05)$. No significant differences were found concerning catecholamines although the group with a high level of symptoms showed higher values on these measures as compared to the other groups. Finally, no differences were found with regard to smoking, body mass index, or medication of any kind.

\section{Conclusion}

It was concluded that common, medically unexplained symptoms among women, being the main cause for seeking primary health care, are associated with elevated levels of physiological stress responses known to play a role in the development of various health problems and diseases.

\section{General discussion}

The overriding aim of this thesis was to explore the associations between subjective evaluations of health among women in terms of self-rated health and common symptoms, and objective health measures involving medical examinations and physiological stress markers. Moreover, women's health was put in a developmental context, physiologically as well as psychosocially. 
The results presented indicate a generally high agreement between self- and physicianratings of general health status (Study I). However, it seems to be the case that physicians take both the reports of their patients as well as their own clinical knowledge and experience into account when making ratings of general health. In contrast, the self-ratings of health were only predicted by the symptom reports of the women themselves. This is in line with previous research showing that after seeing a doctor, patients return to their own explanations of their symptoms and health problems irrespective of the doctor's diagnosis (Hunt et al., 1989). One possible explanation for the phenomenon that physician information is only one component in patients' understanding of their symptoms is that patients have been found to elaborate on their illness schemata over time, and that these schemata are dynamic and fluctuate through time (Hunt et al., 1989). In this context, it has been suggested that self-rated health might influence the perception and interpretation of symptoms, such as if a person rates his/her health as poor, then he/she is likely more attentive to bodily stimuli, and more prone to interpret such stimuli as symptoms and indicators of disease (Idler, 1993). However, this process might also operate in the opposite direction, so that people who rate their health as good are prone to interpret symptoms as normal, temporary states. The potential reasons behind this have been explored in a qualitative study on the meaning of pain, in which it was found that women regarded their pains and symptoms due to various medical conditions as intruders or invaders to their bodies, as an entity separated from their real identities (Johansson, Hamberg, Westman \& Lindgren, 1999). Moreover, coping and the perception of control have been found to be important mediating factors in the interpretation of symptoms and illness (Newman, 1997). Thus, coping and sense of control might be some of the factors involved in the strategies of maintaining perceptions and evaluations of symptoms, which in turn might explain the 
stability found in self-ratings of health, as well as differences between physicians and laypeople in making evaluations of health.

In this context, it is noteworthy that although SRH has been shown to be a strong predictor of future health problems and disease, these conditions themselves did not emerge as strong predictors of SRH (Study I). One exception to this was the symptom "a sense of powerlessness", which alone accounted for the largest part of the explained variance in SRH (20\% of a total of 24\%). Powerlessness resembles the concept of helplessness and hopelessness as negative aspects of coping described by Ursin (2000). These states are assumed to lead to sustained activation of the bodily stress systems, particularly the HPA axis and the secretion of cortisol, which in turn produces physiological, endocrine, and immune changes detrimental to health (Ursin, 2000), whereby cortisol has been associated with a down-regulation of immune activity (Kunz-Ebrecht et al., 2003). For instance, in a study by Benschop and colleagues (1998), individuals showing high cardiac sympathetic activation in response to acute stress also showed magnified cortisol responses assumed to be a mechanism for longerterm immunomodulation. In addition, sustained and prolonged activation of the HPA axis has been associated with high anxiety levels (Song et al., 1999). Feelings of powerlessness, hopelessness and loss of control are also major components in the concept of depression, whereas depression is often associated with higher levels of cortisol (Holsboer, 2000).

Extending this theme, results from previous research have suggested that prolonged dysregulation of the endocrine system related to depression might also play an important role in the development of medical illness and physical morbidity (Barefoot \& Schroll, 1996; Chrousos \& Gold, 1998; Glassman \& Shapiro, 1998; Gold \& 
Chrousos, 1999; Vaillant, Orav, Meyer, McCullough Vaillant, \& Roston, 1996). In this context, powerlessness might be a psychological key component in explaining the power of SRH in predicting future morbidity and mortality in that this emotional state over time might lead to impaired immune activity due to elevated levels of cortisol. In the present thesis (Study IV), women reporting higher levels of common symptoms also showed symptom levels. In contrast, but supportive of this reasoning, are results from a study on positive health in which a link between low cortisol release and high psychological well being was found; an important component that emerged was environmental mastery (Lindfors, 2002).

A particularly interesting finding in the present thesis regards the stability found in symptom reporting over time. In Study II it was revealed that there was longitudinal individual stability in symptom reporting for nearly thirty years; that is, more females than expected by chance who reported a high symptom load in adolescence still did so in middle-age, whereas more females than expected of those reporting low symptom frequencies in adolescence also reported being symptom-free in middle-age. In adolescence, symptom reporting was related with menarcheal timing. However, the group reporting a high symptom load decreased between ages 15 and 43, and in middleage the effect of menarcheal timing on symptom reporting was no longer present. This could be explained by the fact that, as stated in Study II, early-maturing girls do not have the same time as other girls do to adapt to the new demands and challenges associated with adolescence, or to learn the skills necessary to handle these new situations efficiently, resulting in increased stress and elevated symptom reporting. However, during the course of development their coping skills increase with a resulting decrease in symptom reporting. Thus, no effect of menarcheal timing on health could be 
found in middle-age. However, the remaining group of females still reporting a high symptom load in middle-age did so irrespective of their timing of menarche. As such, it was concluded that a high level of symptoms in adolescence per se is related with continued elevations in symptom reporting. It should be pointed out, however, that the number of females included in the longitudinal analyses were few, resulting in a low number of females in each of the emerging cluster solutions. Individual stability in reporting a high frequency of symptoms was found for only nine females, although this was more than expected by chance alone $(4.1, p<.05)$. It follows from this that for a small number of adolescent females reporting a high frequency of symptoms there is an increased risk for poor health development extending even into middle-age. However, the possible factors related with symptom reporting early in life involved in this developmental process, as well as the factors related with the development of a high level of symptoms at later points in time, merit further investigation.

When placing self-reports of general health and common physical and mental symptoms in a psychosocial context (Study III) it was found that poor psychosocial conditions mainly in terms of low income, financial worries and job strain predicted poor self-reported health. These results support previous research that has consistently shown associations between socioeconomic status (SES) and psychosocial factors with health outcomes. For instance, SES, often defined in terms of educational level, income, and job position, has been found to be inversely related to coronary artery disease (van Rossum, van de Mheen, Witteman, Mackenbach, \& Grobbee, 1999), affective disorders (Lewis, Bebbington, Brugha, Farrell, Jenkins, \& Meltze, 1998), autoimmune illness (Rossou, Kennedy, Garrett, \& Calin, 1997) and infectious diseases (Cohen, 1999). These SES gradients in disease might be due to activation of the central nervous system (Steptoe \& Marmot, 2002), in that psychosocial factors are associated with mental 
stress, which in turn exerts an influence on immune processes (Zorrilla, Luborsky, McKay, Rosenthal, Houldin, Tax, McCorkle, Seligman, \& Schmidt, 2001). In support of this are results showing that lower SES groups experience more chronic stress in terms of higher work and financial stress than do individuals in more privileged groups (Marmot, Bosma, Hemingway, Brunner, \& Stansfeld, 1997; Taylor \& Seeman, 1999).

In particular, the construct of job strain, developed by Karasek and Theorell in their demand-control model (1990), has been identified as a potent risk factor for health complaints and psychological distress (Bourbonnais, Comeau, \& Vezina, 1999; Cheng, Kawachi, Coakley, Schwartz, \& Colditz, 2000; de Jonge, Bosma, Peter, \& Siegrist, 2000). Additional factors contributing to stress that might increase risk of psychological distress and health problems are conflicts between work and home, as well as problems associated with domestic responsibilities (Allen, Herst, Bruck, \& Sutton, 2000). Thus, although several studies point to the benefits in terms of psychological well being of paid employment this might be offset by additional burdens, particularly for parents (Sogaard, Kritz-Silverstein, \& Wingard, 1994; Waldron \& Jacobs, 1989).

Negative health outcomes have been proposed to be especially relevant for women as they still tend to assume prime responsibility for most domestic tasks, even in dualearning families (Berntsson, Krantz, \& Lundberg, submitted; Hunt \& Annandale, 1993; Lundberg, Mårdberg, \& Frankenhaeuser, 1994). As women have also been found to earn less, occupy less prestigious positions at work (Emslie, Hunt \& Macintyre, 1999, Szulkin \& Thålin, 1994) and experience lower control and higher job strain than men do (Fritzell \& Lundberg, 2000; Hall, 1992), women are at a heightened risk for developing stress-related health problems. This has been supported not only by the higher prevalence of symptom reporting among women, but also in terms of sickness 
leave in showing an association with job strain (Evans \& Steptoe, 2002). The above was also confirmed in the present thesis (Study III) in that the combined effect of job strain and unpaid household work, i.e., double burden, increased the risk for both a high level of common symptoms and poor self-rated health, indicating a synergistic effect of these two risk factors. Thus, working conditions, total workload, domestic responsibilities and children influence women's health development in a multifactorial way. This is in concordance with the previously described biopsychosocial model (Frankenhaeuser \& Johansson, 1981; Levi et al., 1982), the demand-control model (Karasek \& Theorell, 1990) and the multiple role hypothesis (Sorensen \& Verbrugge, 1987) attempting to explain the link between stress and health. The common theme in these models is that an imbalance between demands, both at and outside work, and a lack of resources of the individual to meet these demands result in stress that in a longterm perspective leads to ill health.

Throughout this thesis it has been discussed that feelings of powerlessness might be a key component in health development. In this context, the concept of powerlessness could be regarded as similar to a lack of control. This condition is assumed to be the case particularly for women, due to their specific life circumstances often including poor work conditions and low income, as well as holding the main responsibility for taking care of children and household. These living conditions are in turn believed to lead to increased stress and few possibilities for rest and unwinding. As such, the conditions that characterize primarily the lives of women might be considered as chronic states of stress, which are known to be associated with the development of ill health and disease, as suggested by the allostatic load model (McEwen, 1998). Within this model, continuously ongoing stress due to a lack of rest and recovery is presumed 
to lead to allostatic overload, which in turn results in chronic elevations of stress hormones involved in the development of ill health and disease.

However, it should be noted that the symptom "a sense of powerlessness" was only included in the analyses in Study I in the present thesis. This was because, although predictive for self-rated health, only 7.2\% ( $\mathrm{n}=35$ of 488, total sample mean 3.55, sd 0.69; min 1=daily, max 4=never) of the study population reported a high prevalence of feelings of powerlessness (1=daily; $2=$ several times per week). The inclusion criteria for symptoms in Studies III and IV in this thesis were based on ones most commonly reported by the total study population. Thus, in Study III it was decided to include only the symptoms reported by at least ten percent of the study population (8 symptoms), whereas in Study IV the ten most commonly reported symptoms were included as we also wanted to investigate common mental symptoms, which were directly below the ten-percent limit of symptoms reported by the study population (nervousness/worry: daily-several times per week=9.3\%; sadness: dailyseveral times per week=8.4\%).

To test the presumed associations between psychosocial conditions, SRH, powerlessness, and cortisol, additional bivariate Pearson product correlations were calculated $(n=210)$ when the women were 43 years old. The results revealed significant associations between cortisol elevations and poor SRH $(0.17, p<.05)$ as well as between cortisol elevations and low income $(0.20, p<.05)$. Poor SRH was in turn significantly related with financial worries $(0.22, p<.01)$ and a sense of powerlessness $(0.35, p<.0001)$. Moreover, there was a tendency toward significance between poor SRH and unpaid household work $(0.16, p<.056)$. Powerlessness was found to be 
associated with job strain $(0.17, p<.05)$, and job strain was in turn significantly related with short educational level at both ages $26(0.20, p<.01)$ and $43(0.20, p<.01)$.

Taken together, the results of these additional analyses bind together the findings from the studies included in this thesis, supporting the notion that in the context of health development among women there are several important factors operating simultaneously. In particular, poor psychosocial conditions mainly in terms of job strain, financial worries, low income, and double exposure are presumed to lead to a high level of common, medically unexplained symptoms, especially feelings of powerlessness, as well as poor SRH and elevated cortisol levels. Thus, these factors are intertwined in a complex and multidirectional manner, operating together in the development of symptoms and poor SRH among middle-aged women. This falls within the general theoretical framework constituting the basis for this thesis, the holistic, interactionistic paradigm, in proposing that individual development and functioning is a dynamic, complex, and reciprocal process taking place in continuous time between factors within the individual, i.e., biological, mental, and behavioural, as well as between the individual and the components in the environment constituting the framework of her life in which she acts.

From the results presented in this thesis it can be hypothesized that women's symptoms could be reduced if their overall life circumstances were improved. The practical implications of this might include a redesign and development of the labour market towards giving women, as well as men, more influence and control over their lives, both at and away from work. Moreover, it is emphasized that in the clinical setting, primary care staff need a better understanding of the individual woman seeking health care because of common, medically unexplained symptoms. The reasons behind these 
symptoms merit further investigation with regard to women’s overall life circumstances with special focus on trying to understand the meaning of the symptoms from the woman's perspective. Thus, it is important to place the symptoms in the context of her life story, and not only focus on single symptoms in relation to specific organs and their possible dysfunction from a strictly medical point of view.

\section{Shortcomings and limitations}

It should first be noted that the studies included in this thesis were carried out with white, middle-aged women; thus the results might not generalise to other groups.

Concerning Study I, in which self-ratings of health were compared with physicianratings, physiological health measures were not included. Although we used medical examinations in comparing health evaluations made by the women with the ratings made by physicians, these examinations consisted of a routine health check-up including a meeting with the women. As such, it is possible that the physicians based their evaluations of the women's overall health largely on the symptom reports of the women. This was also confirmed by the fact that physician-ratings of general health status were predicted by their own ratings of current health problems as well as by the women's self-reports of various symptoms. However, the aim of Study I was to make exactly this kind of comparison to investigate whether there was a correspondence between self- and physician-ratings of health, and how common symptoms and health problems predict ratings of general health. Therefore, this might not necessarily be considered a limitation. However, a better understanding for how physicians rate the health of their patients might have been achieved if we had included traditional physiological health measures as well. Moreover, in the future, it would be interesting 
to investigate the cases in which there was no correspondence between the women's self-ratings of health and the physician-ratings, as well as which factors determine whether or not patients and physicians agree in their evaluations of general health status.

Concerning Study IV, we did not apply a prospective, longitudinal design. As such, direction of causality could not be stated. Moreover, we do not know whether we measured acute or chronic stress. However, as significant findings emerged concerning cortisol, assumed to reflect more long-term, negative stress (Kirschbaum \& Hellhammer, 1998; Lundberg, 1995; 2000), it is reasonable to assume that we captured chronic stress responses.

\section{Concluding remarks}

This thesis has contributed to elucidating some of the associations between subjectively and objectively measured aspects of women's health and stress. Moreover, possible physiological mechanisms linking psychological and psychosocial experiences to health outcomes were discussed. However, future studies are needed within this important area of research. In particular, longitudinal investigations are critical if we are to better understand the processes involved in the development of good or poor health. In this context, another central consideration is the various developmental pathways that possibly lead to identical symptoms and health problems. 


\section{References}

Abraham, E. (1991). Effects of stress on cytokine production. Methods and Achievements in Experimental Pathology, 14, 45-62.

Allen, T. D., Herst, D. E., Bruck, C. S., \& Sutton, M. (2000). Consequences associated with work-to-family conflict: A review and agenda for future research. Journal of Occupational Health Psychology, 5, 278-308.

American Psychiatric Association. (1994). Diagnostic and Statistical Manual of Mental Disorders $\left(4^{\text {th }}\right.$ ed). Washington DC: Author.

Amick, B. C., McDonough, P., Chang, H., Rogers, W. H., Pieper, C. F., \& Duncan, G. (2002). Relationship between all-cause mortality and cumulative working life course psychosocial and physical exposures in the United States labor market from 1968 to 1992. Psychosomatic Medicine, 64, 370-381.

Appels, A., Bosma, H., Grabauskas, V., Gostautas, A., \& Sturmans, F. (1996): Selfrated health and mortality in a Lithuanian and a Dutch population. Social Science

and Medicine, 42, 681-689.

Aro, H., \& Taipale, V. (1987). The impact of puberty on psychosomatic symptoms among

fourteen to sixteen-year old Finnish girls. Child Development, 58, 261-268.

Barefoot, J. C., \& Schroll, M. (1996). Symptoms of depression, acute myocardial infarction, and total mortality in a community sample. Circulation, 93, 19761980.

Barsky, A. J., Cleary, P. D., \& Klerman, G. L. (1992): Determinants of perceived health status of medical outpatients. Social Science and Medicine, 34, 1147-1154.

Benschop, R. J., Geenen, R., Mills, P. J., Naliboff, B. D., Kiecolt-Glaser, J. K., Herbert, $\mathrm{T}$. 
B., van der Pomp, G., Miller, G. E., Matthews, K. A., Godaert, G. L. R., Gilmore,

S., Glaser, R., Heijnen, C. J., Dopp, J. M., Bijlsma, J. W. J., Solomon, G. F., \&

Cacioppo, J. T. (1998). Cardiovascular and immune responses to acute

psychological stress in young and old women: A meta-analysis. Psychosomatic Medicine, 60, 290-296.

Bergman, L. R. (1998). A pattern-oriented approach to studying individual development:

Snapshots and processes. In R. B. Cairns, L. R. Bergman, \& J. Kagan (Eds.), Methods and models for studying the individual (pp. 83-121). Thousand Oaks, CA: Sage.

Bergman, L. R. (2000). 'Women's health, work, and education in a life-span perspective.

Reports from the project Individual Development and Adaptation, No 70. Department of Psychology, Stockholm University.

Bergman, L. R., \& Magnusson, D. (1997). A person-oriented approach in research on developmental psychopathology. Development and Psychopathology, 9, 291319.

Bergman, L. R., Magnusson, D., \& El-Khouri, B., M. (2003). Studying Individual Development in an Interindividual Context. New jersey: Erlbaum.

Bergman, L. R., \& Wångby, M. (1995). The age girl: Patterns of self-reported adjustment problems and some correlates. International Journal of Methods in Psychiatric Research, 5, 171-188.

Berntsson, L., Krantz, G., \& Lundberg, U. (submitted 2003). Total workload: The distribution of paid and unpaid work as related to age, occupational level and number of children among Swedish male and female white-collar workers. 
Björner, J. B., Söndergaard-Kristensen, T., Orth-Gomér, K., Tibblin, G., Sullivan, M., \&

Westerholm, P. (1996): Self-rated health. a useful concept in research, prevention and clinical medicine. Swedish council for planning and coordination of research.

Björntorp, P. (1996). Behavior and metabolic disease. International Journal of Behavioral Medicine, 3, 285-302.

Björntorp, P., \& Rosmond, R. (2000). The metabolic syndrome-a neuroendocrine disorder? British Journal of Nutrition, 83, Suppl. 1, 49-57.

Bobak, M., Pikhart, H., Hertzman, C., Rose, R., \& Marmot, M. (1998): Socioeconomic factors, perceived control and self-reported health in Russia. A cross-sectional survey. Social Science and Medicine, 47, 269-279.

Bohner, G., Bless, H., Schwartz, N., \& Strack, F. (1988). What triggers causal attributions? The impact of valence and subjective probability. European Journal of Social Psychology, 18, 335-345.

Borg, V., \& Kristensen, T. S. (2000). Social class and self-rated health: Can the gradient

be explained by differences in life style or work environment? Social Science and Medicine, 51, 1019-1030.

Bosma, H., Peter, R., Siegrist, J., \& Marmot, M. (1998). Alternative job stress models and

risk of coronary heart disease. The effort-reward imbalance model and the job strain model. American Journal of Public Health, 88, 68-74.

Bourbonnais, R., Comeau, m., \& Vezina, M. (1999). Job strain and evolution of mental health among nurses. Journal of Occupational Health Psychology, 4, 95-107. 
Bradford, V. P., Graham, B. P., \& Reinert, K. G. (1993): Accuracy of self-reported health histories: A study. Military Medicine, 158, 263-265.

Breetvelt, I. S., \& van Dam, F. S. A. M. (1991): Underreporting by cancer patients: The case of response-shift. Social Science and Medicine, 32, 981-987.

Brosschot, J. F. (2002). Cognitive-emotional sensitization and somatic health complaints.

Scandinavian Journal of Psychology, 43, 113-121.

Cacioppo, J. T., Andersen, B. L., Turnquist, D. C., \& Tassinary, L. G. (1989):

Psychophysiological comparison theory: On the experience, description, and assessment of signs and symptoms. Patient Education and Counseling, 13, 257270.

Cannon, W. B. (1935). Stresses and strains of homeostasis. American Journal of Medical Science, 189, 1-14.

Caspi, A., Lynam, D., Moffitt, t. E., \& Silva, P. A. (1993). Unraveling delinquency:

Biological, dispositional, and contextual contributions to adolescent misbehavior. Developmental Psychology, 29, 19-30.

Cheng, Y., Kawachi, I., Coakley, E. H., Schwartz, J., \& Colditz, G. (2000) Association between psychosocial work characteristics and health functioning in American women: Prospective study. British Medical Journal, 320, 1432-1436.

Craaford, K. (1972). Problem behavior and problem-girls in early youth. A study of 15year-old girls. Unpublished licentiate thesis, Department of Psychology, Stockholm University.

Chrousos, G. P., \& Gold, P. W. (1992). The concepts of stress system disorders:

Overview of behavioral and physical homeostasis. Journal of American Medicine Association, 267, 1244-1252. 
Chrousos, G. P., \& Gold, P. W. (1998). A healthy body in a healthy mind-and vice versa-

the damaging power of ÒuncontrollableÓ stress. Journal of Clinical Endocrinology and Metabolism, 83, 1842-1845.

Cioffi, D. (1991): Beyond attentional strategies: A cognitive-perceptual model of somatic $\quad$ interpretation. Psychological Bulletin, 109, 25-41.

Cohen, F. (1984): Coping. In J. D Matarazzo (Ed.), Behavioural health: A handbook of health enhancement and disease prevention. New York: Wiley.

Cohen, S. (1999). Social status and susceptibility to respiratory infections. Annals of the New York Academy of Sciences, 896, 246-253.

Cohen, S., Miller, G. E., \& Rabin, B. S. (2001). Psychological stress and antibody response to immunization: A critical review. Psychosomatic Medicine,63, 7-18.

Costa, P. T., \& MacCrae, R. R. (1985): Hypochondrias, neuroticism , and aging: When are somatic complaints unfounded? American Psychologist, 40, 19-28.

de Jonge, J., Bosma, H., Peter, R., \& Siegrist, J. (2000). Job strain, effort-reward imbalance and employee well-being: A large-scale cross-sectional study. Social Science and Medicine, 50, 1317-1327.

Dhabhar, F., \& McEwen, B. S. (1998). Enhancing versus suppressive effects of tress hormones on skin immune function. Proclamations in the National Academic Sciences USA, 96, 1059-1064.

Dallman, M. F., Bhatnagar, S., \& Viau, V. (2000). Hypothalamo-pituitary-adrenal axis. In

G. Fink (Eds.), Encyclopedia of stress Vol. 2 (pp. 468-477). San Diego, CA: Academic Press.

Diener, E. (1984): Subjective well-being. Psychological Bulletin, 95, 542-575.

Doornen, L J. P. van, Snieder, H., \& Boomsma, D. I. (1998). Serum lipids and 
cardiovascular reactivity to stress. Biological Psychology, 47, 279-297.

Elam, J. T., Graney, M. J., Beaver, T., el Derwi, D., Applegate, W. B., \& Miller, S. T. (1991): Comparison of subjective ratings of function with observed functional ability of frail older persons. American Journal of Public Health, 81, 1127-1130.

Emslie, C. Hunt, K., \& Macintyre, S. (1999). Problematizing gender, work and health: The relationship between gender, occupational grade, working conditions and minor morbidity in full-time bank employees. Social Science and Medicine, 48, 33-48.

Evans, O., \& Steptoe, A. (2003). The contribution of gender-role orientation, work factors

and home stressors to psychological well-being and sickness absence in male- and female-dominated occupational groups. Social Science and Medicine, 54, 481492.

Felten, S., \& Felten, D. (1994). Neural-immune interactions. Progressions in Brain Research, 100, 157-162.

Ferrie, J. E., Shipley, M. J., Stansfeld, S. A., Davey Smith, G., \& Marmot, M. (2003).

Future uncertainty and socioeconomic inequalities in health: The Whitehall study

II. Social Science and Medicine (in press).

Forman, S. G. (1993). Coping skills intervention during Childhood and Adolescence.

San Francisco: Jossey-Bass.

Frankenhaeuser, M., \& Johansson, G. (1981). On the psychophysiological consequences

of understimulation and overstimulation. In L. Levi (Ed. ), Society, Stress, and Disease. Vol 4, Working Life (pp. 82-89). Oxford University Press. 
Franks, P., Gold, M. R., \& Fiscella, K. (2003). Sociodemographics, self-rated health, and

mortality in the US. Social Science and Medicine (in press).

Fritzell, J., \& Lundberg, O. Welfare, disadvantage, and inequality. Stockholm: SOU 2000:

41 pp. 56-60.

Fylkesnes, K., \& Forde, O. H. (1991): The Tromso study: Predictors of self-evaluated health-has society adopted the expanded health concept? Social Science and Medicine, 32, 141-146.

Ge, X., Conger, R. D., \& Elder, G. H. Jr. (1996). Coming of age too early: Pubertal influences on girls’ vulnerability to psychological distress. Child Development, 67, 3386-3400.

Ge, X., Conger, R. D., \& Elder, G. H. Jr. (2001). Pubertal transition, stressful life events,

and the emergence of gender differences in adolescent depressive symptoms. Developmental Psychology, 37, 404-417.

Gijsbers van Wijk, C. M. T., \& Kolk, A. M. (1997). Sex differences in physical symptoms: The contribution of symptom perception theory. Social Science and Medicine, 45, 231-246.

Gijsbers van Wijk, C. M. T., Huisman, H., \& Kolk, A. M. (1999). Gender differences in physical symptoms and illness behavior: A health diary study. Social Science and Medicine, 49, 1061-1074.

Gjesdal, S., \& Bratberg, E. (2002). The role of gender in long-term sickness absence and

transition to permanent disability benefits. Results from a multiregister-based, 
prospective study in Norway 1990-1995. European Journal of Public Health, 12 ,

180-186.

Glassman, A. H., \& Shapiro, P. A. (1998). Depression and the course of coronary artery disease. American Journal of Psychiatry, 155, 4-11.

Gold, P. W. \& Chrousos, G. P. (1999). The endocrinology of melancholic and atypical depression: Relation to neurocircuitry and somatic consequences. Proceedings of the Association of American Physicians, 111, 22-34.

Goldstein, M. S., Siegel, J. M., \& Boyer, R. (1984): Predicting changes in perceived health status. American Journal of Public Health, 74, 611-614.

Gore, S., \& Mangione, T. W. (1983). Social roles, sex roles, and psychological distress: Additive and interactive models of sex differences. Journal of Health and Social Behavior, 24, 300-312.

Graber, J. A., Brooks-Gunn, J. (1996). Transitions and turning points: Navigating the passage from childhood through adolescence. Developmental Psychology, 32, 768-776.

Graber, J. A., Lewinsohn, P. M., Seeley, j. R., \& Brooks-Gunn, J. (1997). Is psychopathology associated with the timing of pubertal development? Journal of American Child and Adolescent Psychiatry, 36, 1768-1776.

Hall, E.M. (1992). Double exposure: the combined impact of the home and work environment on psychosomatic strain in Swedish women and men. International Journal of the Health Services, 22, 239-260.

Hammarström, A., Härenstam, A., \& Östlin, P. (1996). Gender and ill health-concepts and 
explanatory models. In Östlin, P., Danielsson, M., Diderichsen, F., Härenstam, A., \& Lindbeerg, G. (Eds.), Gender and ill health-an anthology on sex differences from a public health perspective (pp 7-28). Lund, Studentlitteratur. Hammarström, A. (1991). Health from a gender perspective. Socialmedicinsk Tidskrift, 68, 177-181.

Hammarström, A. (2002). What could a gender perspective mean in medical and public-

health research? In S. P. Wamala \& J. Lynch (Eds.), Gender and Social Inequities in Health, pp. 21-37. Lund: Studentlitteratur.

Harding, S. (1986). Feminism and methodology: Social science issues. Bloomington, Indiana University Press.

Heidrich, S. M. (1993): The relationship between physical health and psychological well- being in elderly women: A developmental perspective. Research on Nursing and Health 16, 123-130.

Helmer, C., Barberger-Gateau, P., Letenneur, L., \& Dartigues, J. F. (1999): Subjective health and mortality in French elderly women and men. Journal of Gerontology in

the Psychological Sciences and Social Sciences, 54, 84-92.

Hemingway, H., Nicholson, A., Stafford, M., Roberts, R., \& Marmot, M. (1997). The impact of socio-economic status on health functioning as assessed by the SF-36 questionnaire: The Whitehall II study. American Journal of Public Health, 87, 1484-1490.

Henningsen, P., Zimmermann, T., \& Sattel, H. (2003). Medically unexplained physical symptoms, anxiety, and depression: a meta-analytic review. Psychosomatic Medicine, 65, 528-533.

Henry, J. (1992). Biological basis of the stress response. News in Physiological Science, 
8, 69-73.

Henry, J. (1993). Psychological and physiological responses to stress: The right hemisphere and the hypothalamic-pituitary-adrenal-axis. An inquiry into problems of human bonding. Integrative Physiological and Behavioral Science, 28, 368-387.

Hibbard, J. H., \& Pope, C. R. (1993). The quality of social roles as predictors of morbidity and mortality. Social Science and Medicine, 36, 217-225.

Hirdman, Y. (1988). The gender system-reflections on women's 'subordinate position. Kvinnovetenskaplig Tidskrift, 3, 49-63.

Holsboer, F. (2000). The corticosteroid receptor hypothesis of depression. Neuropsychopharmacology, 23, 477-501.

Hunt, K., \& Annandale, E. (1993). Just the job? Is the relationship between health and domestic and paid work gender-specific? Sociology of Health and Illness, 15, $632-$

664.

Hunt, L. M., Jordan, B., \& Irwin, S. (1989): Views of what's wrong: diagnosis and patients’ concepts of illness. Social Science and Medicine, 28, 945-956.

Ibrahim, S. A., Scott, F. E., Cole, D. C., Shannon, H. S., \& Eyles, J. (2001). Job strain and

self-reported health among working women and men: An analysis of the 1994/95

Canadian national population health survey. Women and Health, 33, 105-124.

Idler, E. L., \& Angel, R. J. (1990): Self-rated health and mortality in the NHANES-I epidemiologic follow-up study. American Journal of Public Health, 80, 446452.

Idler, E. L . (1993): Perceptions of pain and perceptions of health. Motivation and 
Emotion, 17, 205-224.

Idler, E. L., \& Benyamini, Y. (1997): Self-rated health and mortality: A review of twenty-

seven community studies. Journal of Health and Social Behavior, 38, 21-37.

Johansson, E. E., Hamberg, K., Westman, G., \& Lindgren, G. (1999). The meanings of pain: An exploration of 'women's descriptions of symptoms. Social Science and Medicine, 48, 1791-1802.

Johnson, T. P., Stallones, L., Garrity, T. F., \& Marx, M. B. (1991: Components of selfrated health among adults: Analysis of multiple data sources. International Quarterly of Community Health and Education, 11, 29-41.

Johnson, R. J., \& Wolinsky, F. D. (1993): The structure of health status among older adults: Disease, disability, functional limitation, and perceived health. Journal of

Health and Social Behavior, 34, 105-121.

Jylhä, M. (1994): Self-rated health revisited: Exploring survey interview episodes with elderly respondents. Social Science and Medicine, 39, 983-990.

Jylhä, M., Leskinen, E., Alanen, E., \& Leskinen, A. L. (1986): Self-rated health and associated factors among men of different ages. Journal of Gerontology, 41, $710-$

717.

Jylhä, M., Guralnik, J. M., Ferrucci, L., Jokela, J., \& Heikkinen, E. (1998): Is self-rated health comparable across cultures and genders? Journal of Gerontology in the Psychological Sciences and Social Sciences, 53, 144-152.

Kalkas, H. (1990): Nursing as a scientific discipline. Scandinavian Journal of Caring Sciences, 4, 57. 
Kaplan, G. A., \& Camacho, T. (1983). Perceived health and mortality. A nine year follow-

up of the human population laboratory cohort. American Journal of Epidemiology, 117, 292-304.

Karasek, R. (1979). Job demands, job decision latitude and mental strain: Implications for

job redesign. Administrative Science Quarterly, 24, 285-307.

Karasek, R., \& Theorell, T. (1990). Healthy work. Stress, productivity and the reconstruction of working life. New York: Basic Books.

Kawachi, I., Kennedy, B. P., \& Glass, R. (1999): Social capital and self-rated health:

A contextual analysis. American Journal of Public Health, 89, 1187-1193.

Kelleher, C. C., Friel, S., Nic Grabhainn, S., \& Tay, J. B. (2003). Socio-demographic predictors of self-rated health in the Republic of Ireland: Findings from the National Survey on Lifestyle, Attitudes, and Nutrition, SLAN. Social Science and

Medicine (in press).

Kempen, G. I., Jelicic, M., \& Ormel, J. (1997): Personality, chronic medical morbidity, and health-related quality of life among older persons. Health Psychology, 16, 539-546.

Kempen, G. I., Miedema, I., van den Bos, G. A., \& Ormel, J. (1998): Relationship of domain-specific measures of health to perceived overall health among older subjects. Journal of Clinical Epidemiology, 51, 8-11.

Kennedy, B. P., Kawachi, I., Glass, R., \& Prothrow-Stith, D. (1998): Income distribution, socioeconomic status, and self-rated health in the United States: Multilevel analysis. British Medical Journal, 317, 917-921. 
Kirschbaum, C., \& Hellhammer, D. H. (1989). Salivary cortisol in psychobiological research: An overview. Neuropsychobiology, 22, 150-169.

Kirschbaum, C., Scherer, G., \& Strasburger, C. J. (1994). Pituitary and adrenalhormone

responses to pharmacological, physical, and psychological stimulation in habitual

smokers and nonsmokers. Clinical Investigator, 72, 804-810.

Kivinen, P., Halonen, P., Eronen, M., \& Nissinen, A. (1998): Self-rated health, physician-rated health and associated factors among elderly men: The Finnish cohorts of the Seven Countries Study. Age and Ageing, 27, 41-47.

Kollack-Walker, S., Day, H. E. W., \& Akil, H. (2000). Central stress neurocircuits. In G.

Fink (Eds.), Encyclopedia of stress Vol. 1 (pp. 414-423). San Diego, CA: Academic Press.

Krantz, G., Berntsson, L., \& Lundberg, U. (submitted 2003). Total work load, work stress,

and symptom perception in Swedish male and female white collar employees.

Krantz, G., \& Östergren, P-O. (1999) Women’s health: do common symptoms in women mirror general distress or specific disease entities? Scandinavian Journal

of Public Health, 27, 311-317.

Krantz, G., \& Östergren, P-O. (2001). Double exposure: The combined impact of domestic responsibilities and job strain on common symptoms in employed Swedish women. European Journal of Public Health, 11, 413-419.

Krause, N. M., \& Jay, G. M. (1994): What do global self-rated health items measure? Medical Care, 32, 930-942. 
Kunz-Ebrecht, S. R., Mohamed-Ali, V., Feldman, P. J., Kirschbaum, C., \& Steptoe, A. (2003). Cortisol responses to mild stress are inversely associated with proinflammatory cytokines. Brain, Behavior, and Immunity, 17, 373-383.

Lahelma, E., Arber, S., Kivelä, K., \& Roos, E. (2002). Multiple roles and health among British and Finnish women: The influence of socioeconomic circumstances. Social Science and Medicine, 54, 727-740.

Lazarus, R. S. (1966). Psychological stress and the coping process. New York: McGraw-Hill.

Lazarus, R. S. (1992). Coping theory and research: Past, present, future. Psychosomatic Medicine, 55, 234-247.

Leibson, C. L., Garrard, J., Nitz, N., Waller, L., Indritz, M., Jackson, J., Rolnick, S. J., \& Luepke, L. (1999): The role of depression in the association between selfrated physical health and clinically defined illness. Gerontologist, 39, 291-298.

Leinonen, R., Heikkinen, E., \& Jylhä, M. (1998): Self-rated health and self-assessed change in health in elderly men and women-a five-year longitudinal study. Social

Science and Medicine, 46, 591-597.

Leventhal, H., Diefenbach, M. (1991). The active side of illness cognition. In J. A.

Skelton R. T. Croyle (Eds.), Mental representations in Health and Illness. New York: Springer Verlag.

Leventhal, H., Diefenbach, M., \& Leventhal, EA. (1992): Illness cognition: Using common sense to understand treatment adherence and affect cognition interactions. Cognition and Therapy Research, 16, 143-163.

Levi, L., Frankenhaeuser, M., \& Gardell, B. (1982). Work stress related to social structures and processes. In G. R. Elliot \& C. Eisdorfer (Eds.), Stress and Human Health (pp. 119-146). New York: Springer. 
Levine, S. \& Ursin, H. (1991). What is stress? In M. R. Brown, C. Rivier, and G. Koob (Eds.), Stress, Neurobiology, Neuroendocrinology (pp. 3-21). New York: Marcel Decker.

Lewis, G., Bebbington, P., Brugha, T., Farrell, M., Jenkins, R., \& Meltzer, H. (1998). Socioeconomic status, standard of living, and neurotic disorder. Lancet, 352, 605609.

Liang, J. (1986): Self-reported physical health among aged adults. Journal of Gerontology, 41, 248-260.

Lindén, K. (1991). Women - Health - Action. Doctoral dissertation, Department of Social

Work, Gothenburg University, Sweden.

Lindfors, P., \& Lundberg, U. (2002). Is low cortisol release an indicator of positive health? Stress and Health, 18, 153-160.

Lundberg, U. (1995). Methods and applications in stress research. Technology and Health Care, 3, 3-9.

Lundberg, U. (2000). Catecholamines. In G. Fink (Eds.), Encyclopedia of stress Vol. 1 (pp. 408-413). San Diego, CA: Academic Press.

Lundberg, U. (2002). Gender, multiple roles and physiological reactions. In S. P. Wamala \& J. Lynch (Eds.), Gender and Social Inequities in Health, pp. 123144. Lund: Studentlitteratur.

Lundberg, U., \& Hellström, B. (2002). Workload and morning salivary cortisol in women. Work and Stress, 16, 356-363.

Lundberg, U., Mårdberg, B., Frankenhaeuser, M. (1994). The total workload of male and

female white collar workers as related to age, occupational level, and number of children. Scandinavian Journal of Psychology, 35, 315-327. 
Macintyre, S., Hunt, K., \& Sweeting, H. (1996). Gender differences in health. Are things

really as simple as they seem? Social Science and Medicine, 42, 617-624.

Macintyre, S., Ford, G., \& Hunt, K. (1999). Do women Òover-reportÓ morbidity? Men’s

and 'women's responses to structured prompting on a standard question on long standing illness. Social Science and Medicine, 48,89-98.

Mackenbach, J. P., van den Bos, J., Joung, I. M., van de Mheen, H., \& Stronks, K. (1994):

The determinants of excellent health. Different from the determinants of illhealth?

International Journal of Epidemiology, 23, 1273-1281.

Maddox, G., \& Douglass, E. (1973): Self-assessment of health: A longitudinal study of elderly subjects. Journal of Health and Social Behavior, 14, 87-93.

Magnusson, D. (1988). Individual development from an interactional perspective: A longitudinal study. In D. Magnusson (Ed.), Paths Through Life (Vol 1). Hillsdale,

New Jersey: Erlbaum.

Magnusson, D. (1998). The logic and implications of a person approach. In R. B. Cairns,

L. R. Bergman, \& J. Kagan (Eds.), Methods and Models for Studying the Individual (pp. 33-63). Thousand Oaks, CA: Sage.

Magnusson, D. (2000). The individual as the organizing principle in psychological inquiry. In L. R. Bergman, R. B. Cairns, L. G. Nilsson, \& L. Nystedt (Eds.), Developmental Science and the Holistic Approach (pp. 33-47). Mahwah, New Jersey: Erlbaum. 
Magnusson, D., \& Bergman, L. R. (1997). Individual Development and Adaptation: the IDA-program. Reports from the Department of Psychology, No 841, Stockholm University.

Magnusson, D., \& Cairns, R. B. (1996). Developmental science: Toward a unified framework. In R. B. Cairns, J. G. H. Elder, \& E. J. Costello (Eds.), Developmental Science (pp. 7-30). New York: Cambridge University Press.

Magnusson, D., \& Stattin, H. (1996). Person-context interaction theories. In R. M.

Lerner, \& W. Damon (Eds.), Handbook of child psychology. Theoretical models of human development. ( $5^{\text {th }}$ ed., Vol. 1, pp. 685-759). New York: Wiley.

Maier, S. F. \& Watkins, L. R. (1998). Cytokines for psychologists: Implications of bidirectional immune-to-brain communication for understanding behavior, mood, and cognition. Psychological Review, 105, 83-107.

Malterud, K. (1987a). Illness and disease in female patients. Pitfalls and inadequacies of

primary health care classification systems - a theoretical review. Scandinavian Journal of Primary Health Care, 5, 205-209.

Malterud, K. (1987b). Illness and disease in female patients II. A study of consultation techniques designed to improve the exploration of illness in general practice.

Manderbacka, K. (1998): Examining what self-rated health question is understood to mean by respondents. Scandinavian Journal of Social Medicine, 26, 145-153.

Manderbacka, K., Lundberg, O., \& Martikainen, P. (1999): Do risk factors and health behaviours contribute to self-ratings of health? Social Science and Medicine, 48, 1713-1720.

Marmot, M., Bosma, H., Hemingway, H., Brunner, E., \& Stansfeld, S. (1997).

Contribution of job control and other risk factors to social variations in coronary heart disease incidence. Lancet, 350, 235-239. 
Marmot, M., Ryff, C. D., Bumpass, L. L., Shipley, M., \& Marks, N. F. (1997). Social inequalities in health: Next questions and converging evidence. Social Science and

Medicine, 44, 901-910.

Marschall, P. (1989): Self-report and stability of physical complaints by adolescents. Adolescence, 24, 209-216.

Martikainen, P. (1995). 'Women's employment, marriage, motherhood and mortality: A test of the multiple role and role accumulation hypotheses. Social Science and Medicine, 40, 199-212.

Matthews, S., Manor, O., \& Power, C. (1999): Social inequalities in health: Are there gender differences? Social Science and Medicine, 48, 49-60. Scandinavian Journal of Primary Health Care, 5, 211-216.

McDonough, P., Walters, V., \& Strohschein, L. (2002). Chronic stress and the social patterning of women's health in Canada. Social Science and Medicine, 54, 767782.

McEwen, B. S. (1998). Protective and damaging effects of stress mediators. New England Journal of Medicine, 338, 171-179.

McEwen, B. S. (2000). Effects of adverse experiences for brain structure and function. Biological Psychiatry, 48, 721-731.

McEwen, B. S., \& Seeman, T. (1999). Protective and damaging effects of mediators of stress: Elaborating and testing the concepts of allostasis and allostatic load. Annals

of the New York Academy of Sciences, 896, 30-47.

McEwen, B. S. \& Wingfield, J. C. (2003). The concept of allostasis in biology and biomedicine. Hormones and Behavior, 43, 2-15. 
Meyer, S. E., Chrousos, G. P., \& Gold, P. W. (2001). Major depression and the stress system: A life span perspective. Developmental Psychopathology, 13, 565-580.

Miilunpalo, S., Vuori, I., Oja, P., Pasanen, M., \& Urponen, H. (1997): Self-rated health as a health measure: The predictive value of self-reported health status on the use of physician services and mortality in the working-age population. Journal of Clinical Epidemiology, 50, 517-528.

Moller, L., Kristensen, T. S., \& Hollnagel, H. (1996): Self-rated health as a predictor of coronary heart disease in Copenhagen, Denmark. Journal of Epidemiology and Community Health 50, 423-428.

Mårdberg, B., Lundberg, U., \& Frankenhaeuser, M. (1991). The total workload of parents employed in white collar jobs: Construction of a questionnaire and a scoring system. Scandinavian Journal of Psychology,32, 233-239.

Newman, S. P. (1997): Psychosocial measures in musculoskeletal trials. Journal of Rheumatology 24, 979-984.

Peter, R., \& Siegrist, J. (1997). Chronic work stress, sickness absence, and hypertension in middle managers: General or specific sociological explanations? Social Science and Medicine 45, 1111-1120.

Petersen, A. C., Sirigiani, P. A., Kennedy, R. E. (1991). Adolescent depression: Why more girls? Journal of Youth and Adolescence, 20, 247-271.

Pikhart, H., Siegrist, J., Pajak, A., Rywik, S., Kyshegyi, J., Gostautas, A., Skodova, Z., $\&$

Marmot, M. (2001). Psychosocial work characteristics and self-rated health in four post-communist countries. Journal of Epidemiological and Community Health, 55,624-630.

Popay, J. (1993). My health is all right, but I'm just tired all the time. Women's' experience of ill health. In H. Roberts (Ed.), 'Women's health matters (pp. 99- 
120). London: Routledge.

Puranen, B. (1994). To be a woman is not a disease. Stockholm: Nordstedts Förlag (In Swedish).

Ratner, P. A., Johnson, J. L., \& Jeffery, B. (1998): Examining emotional, physical, social, and spiritual health s determinants of self-rated health status. American Journal of

Health Promotion, 12, 275-282.

Rierdan, J., \& Koff, E. (1991). Depressive symptomatology among very early maturing girls. Journal of Youth and Adolescence, 20, 415-425.

Roberts, G. (1999): Age effects and health appraisal: A meta analysis. Journal of Gerontology, series B in the Psychological Sciences and Social Sciences, 54, 2430.

Rodin, J., \& McAvay, G. (1992): Determinants of change in perceived health in a longitudinal study of older adults. Journal of Gerontology, 47, 373-384.

Roozendaal, B. (2000). Glucocorticoids and the regulation of memory consolidation. Psychoneuroendocrinology 25, 213-238.

Rosenfield, S. (1989). The effects of 'women's employment: Personal control and sex differences in mental health. Journal of Health and Social Behavior 30, 77-91.

Rossou, E., Kennedy, L. G., Garrett, S., \& Calin, A. (1997). Socioeconomic status in ankylosing spondylitis: Relationship between occupation and disease activity. Journal of Rheumatology 24, 908-911.

Ryff, C. D. (1995): Psychological well-being in adult life. Current Directions in the Psychological Sciences 4, 99-104.

Scheier, M. F., \& Carver, C. S. (1985): Optimism, coping, and health: Assessment and implications of generalized outcome expectancies. Health Psychology,4, 219247. 
Scheier, M. F., \& Carver, C. S. (1987): Dispositional optimism and physical wellbeing: The influence of generalized outcome expectancies on health. Journal of Personality, 55, 169-210.

Schreurs, P. J., \& Taris, T. W. (1998). Construct validity of the demand-control model: A

double-cross validation approach. Work and Stress 12, 66-84.

Shadbolt, B. (1997): Some correlates of self-rated health for Australian women. American

Journal of Public Health, 87, 951-956.

Seiffge-Krenke, I. (1995). Stress, Coping and Relationships in Adolescence. Mahwah, New Jersey: Erlbaum.

Selye, H. (1946). The general adaptation syndrome and the disease of adaptation. Journal

of Clinical Endocrinology, 6, 112-230.

Selye, H. (1950). The physiology and pathology of exposure to stress. Montreal: Acta. Siegrist, J. (1996). Adverse health effects of high-effort/low-reward conditions. Journal of

Occupational Health Psychology, 1, 27-41.

Simmons, R. G., Burgeson, R., \& Carlton-Ford, S. (1987). The impact of cumulative change in early adolescence. Child Development, 58, 1220-1234.

Sogaard, A. J., Kritz-Silverstein, D., \& Wingard, D. L. (1994). Finnmark Heart Study: Employment status and parenthood as predictors of psychological health in women, 20-49 years. International Journal of Epidemiology, 23, 82-90.

Song, C., Kenis, G., van Gastel, A., Bosmans, E., Lin, A., de Jong, R., Neels, H., Scharpe, 
S., Janca, A., Yasukawa, K., \& Maes, M. (1999). Influence of psychological stress

on immune-inflammatory variables in normal humans. Part II. Altered serum concentrations of natural anti-inflammatory agents and soluble membrane antigens

of monocytes and T lymphocytes. Psychiatry Research, 85, 293-303.

Sorensen, G., \& Verbrugge, L. . (1987). Women, work, and health. Annual Review of Public Health, 8, 235-251.

Spinhoven, P., Jochems, P. A., Linssen, A. C., \& Bogaards, M. (1991): The relationship of personality variables and patient recruitment to pain coping strategies and psychological distress in tension headache patients. Clinical Journal of Pain, 7,

$12-20$.

Stansfeld, S. A,. Smith, G. D., \& Marmot, M. (1993): Association between physical and psychological morbidity in the Whitehall II Study. Journal of Psychosomatic Research, 37, 227-238.

Stansfeld, A., Bosma, H., Hemingway, H., \& Marmot, M. G. (1998). Psychosocial work

characteristics and social support as predictors of SF-36 health functioning: The Whitehall II study. Psychosomatic Medicine, 60, 247-255.

Starke, D., \& Niedhammer, I. (2002). Gender and effort reward imbalance at work. In S.

P. Wamala \& J. Lynch (Eds.), Gender and Social Inequities in Health, pp. 67-85. Lund: Studentlitteratur.

Stattin, H., \& Magnusson, D. (1990). Pubertal maturation in female development. In D. Magnusson (Ed.), Paths Through Life (Vol 2). Hillsdale, New Jersey: Erlbaum. 
Steptoe, A., \& Marmot, M. (2002). The role of psychobiological pathways in socioeconomic inequalities in cardiovascular disease risk. European Heart Journal, 23, 13-25.

Steptoe, A., Kunz-Ebrecht, S. R., \& Owen, N. (2003). Lack of association between depressive symptoms and markers of immune and vascular inflammation in middle-aged men and women. Psychological Medicine, 33, 667-674.

Stewart, M. (1991). Studies about the patient-centered approach. Huisarts En nshap, 34, 302-305.

Stice, E., Presnell, K., Bearman, S. K. (2001). Relation of early menarche to depression, eating disorders, substance abuse, and comorbid psychopathology among adolescent girls. Developmental Psychology, 37, 608-619.

Stoney, C. M., \& Finney, M. (2000). Cholesterol and lipoproteins. In G. Fink (ed.), Encyclopedia of Stress Vol. 1 (pp. 454-459). San Diego: Academic Press.

Susman, E J., Dorn, l. D., \& Chrousos, G. P. (1991). Negative affect and hormone levels

in young adolescents: Concurrent and predictive perspectives. Journal of Youth and Adolescence, 20, 167-190.

Szulkin, R., \& Thålin, M. Vardagens villkor (Everyday conditions). Stockholm: Brombergs förlag, 1994.

Taylor, S. E., \& Seeman, T. E. (1999). Psychosocial resources and the SES-health relationship. Annals of the New York Academy of Sciences, 896, 210-225.

Theorell, T. (1997). How will future worklife influence health? Scandinavian Journal of

Work, Environment and Health, 23, 16-22. 
Tessler, R., \& Mechanic, D. (1978): Psychological distress and perceived health status. Journal of Health and Social Behavior, 19, 254-262.

Tibblin, G., Bengtsson, C., Furunes, B., \& Lapidus, L. (1990). Symptoms by age and sex.

Scandinavian Journal of Primary Health Care, 8, 9-17.

Tsigos, C., \& Chrousos, G. P. (1994). Physiology of the hypothalamic-pituitary-adrenal axis in health and dysregulation in psychiatric and autoimmune disorders. Endocrinology and Metabolism Clinics of North America, 23, 451-466.

Tsigos, C., \& Chrousos, G. P. (2002). Hypothalamic-pituitary-adrenal axis, neuroendocrine factors and stress. Journal of Psychosomatic Research, 53, 865871.

Ursin, H. (1988). Expectancy and activation: An attempt to systematize stress theory. In D. Hellhammer, I. Florin, and H. Weiner (Eds.), Neurobiological Approaches to human Disease (pp. 313-334). Toronto, Canada: Hubert.

Ursin, H. (1997). Sensitization, somatisation, and subjective health complaints. International Journal of Behavioral Medicine, 4, 105-116.

Ursin,H. (1998). The psychology of psychoneuroendocrinology. Psychoneuroendocrinology, 23, 555-570.

Ursin, H. (2000). Psychosomatic medicine: State of the art. Annals of Medicine, 32, 323-

328.

Vaillant, G. E., Orav, J., Meyer, S. E., McCollough Vaillant, L., \& Roston, D. (1996). Late-life consequences of affective spectrum disorders. International Psychogeriatrics, 8, 13-32.

Van Rossum, C. T., van de Mheen, H., Witteman, J. C., Mackenbach, J. P, \& Grobbee, D. 
E. (1999). Socioeconomic status and aortic atherosclerosis in Dutch elderly people: The Rotterdam Study. American Journal of Epidemiology, 150, 142-148.

Van Yperen, N. W., \& Snijders, T. A. (2000). A multilevel analysis of the demandscontrol model: Is stress at work determined by factors at the group level or the individual level? Journal of Occupational Health Psychology, 5, 182-190.

Vassend, O. (1987): Personality, imaginative involvement, and self-reported somatic complaints: Relevance to the concept of alexithymia. Psychotherapy and Psychosomatics, 47, 74-81.

Vassend, O (1989): Dimensions of negative affectivity, self-reported somatic symptoms, and health-related behaviors. Social Science and Medicine, 28, 29-36.

Verbrugge, L. M. (1982). Sex differentials in health. Public Health Reports, 97, 417437.

Verbrugge, L. M. (1983). Multiple roles and physical health for women and men. Journal

of Health and Social Behavior, 24, 16-30.

Verbrugge, L. M. (1985). Gender and health: An update on hypotheses and evidence. Journal of Health and Social Behavior, 26, 156-182.

Verbrugge, L. M. (1986). Role burdens and physical health of men and women. Women and Health, 11, 47-77.

Verbrugge, L. M., \& Wingard, D. L. (1987). Sex differentials in health and mortality. Women and Health, 12, 103-143.

Vågerö, D. \& Lahelma, E. (1998). Women, work, and mortality. In Orth-Gomér, K., Chesney, M., \& Wenger, N. (Eds.), Women, stress and heart disease. Hillsdale, New Jersey: Erlbaum.

Waldron, I., \& Jacobs, J. A. (1989). Effects of multiple roles on women's’ health- 
evidence from a national longitudinal study. Women and Health, 15, 3-19.

Warren, R. (1994). Wealth and health, health and wealth. Toronto: Queen's printer for Ontario.

Watson, D., \& Pennebaker, J. W. (1989): Health complaints, stress, and distress: Exploring the central role of negative affectivity. Psychological Review,

96, 234-

254.

Weinberger, M., Darnell, J., Tierny, W., Martz, B., Hiner, S., Barker, J., \& Neill, P. (1986): Self-rated health as a predictor of hospital admissions and nursing home placement in elderly public housing tenants. American Journal of Public Health, 76, 457-459.

World Health Organization (1948). WHO constitution. In Basic documents. Geneva: Author.

Wångby, M., Magnusson, D., \& Stattin, H. (2002). Self-perceived psychological health among Swedish teenage girls. Reports from the Department of Psychology, No 79.

Yu, E. S., Kean, Y. M., Slymen, D. J., Liu, W. T., \& Katzman, R. (1998): Selfperceived health and 5-year mortality risks among the elderly in Shanghai, China. American Journal of Epidemiology, 47, 880-890.

Zorrilla, E. P., Luborsky, L., McKay, J. R., Rosenthal, R., Houldin, A., Tax, A., McCorkle, R., Seligman, D. A., \& Schmidt, K. (2001). The relationship of depression and stressors to immunological assays: A meta-analytical review. Brain, Behavior, and Immunology, 15, 199-226.

Åkerstedt, T., \& Levi, L. (1978). Circadian rhythms in the secretion of cortisol, adrenaline, 
and noradrenaline. European Journal of Clinical Investigations, 8, 57-58. 